DIW BERLIN

Discussion Papers

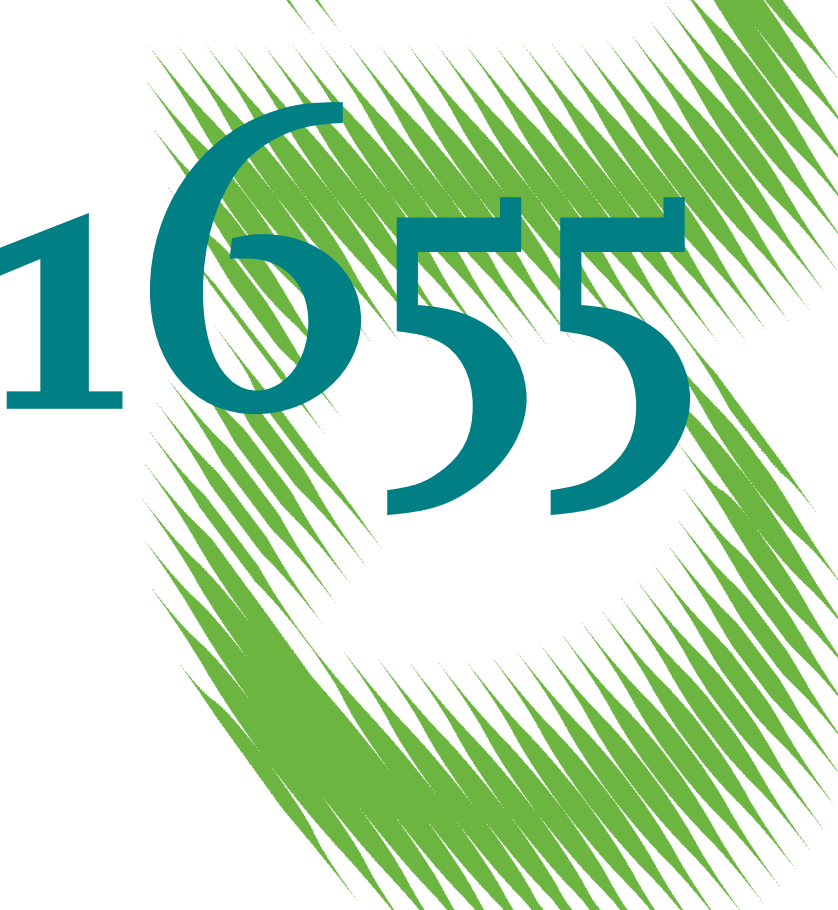

Wind Providing Balancing Reserves - An Application to the German Electricity System of 2025 
Opinions expressed in this paper are those of the author(s) and do not necessarily reflect views of the institute.

IMPRESSUM

(C) DIW Berlin, 2017

DIW Berlin

German Institute for Economic Research

Mohrenstr. 58

10117 Berlin

Tel. +49 (30) $89789-0$

Fax +49 (30) $89789-200$

http://www.diw.de

ISSN electronic edition 1619-4535

Papers can be downloaded free of charge from the DIW Berlin website:

http://www.diw.de/discussionpapers

Discussion Papers of DIW Berlin are indexed in RePEc and SSRN:

http://ideas.repec.org/s/diw/diwwpp.html

http://www.ssrn.com/link/DIW-Berlin-German-Inst-Econ-Res.html 


\title{
Wind providing balancing reserves - An application to the German electricity system of 2025
}

\author{
Casimir Lorenz $^{* \dagger}$ and Clemens Gerbaulet ${ }^{* \dagger}$
}

April 2017

\begin{abstract}
This paper analyzes the influence of wind turbines as new participants on prices and allocation within balancing markets. We introduce the cost-minimizing electricity sector model ELMOD-MIP, that includes detailed unit-commitment constraints, complex combined heat and power constraints, and minimum bid sizes for balancing capacity reservation. The model also features a novel approach of modeling balancing reservation by considering possible activation costs already during the reservation phase, mimicking the activation anticipation of market participants.

The model includes the spot and balancing market of Germany and is applied to scenarios for 2013 and 2025. The results for 2025 show, in comparison to 2013, a price increase for positive and negative reserves, in case no new participants enter the market. With the participation of wind turbines the cost for balancing provision is reduced by $40 \%$, but above 2013 values. The relative cost savings from wind participation are higher for negative reserve provision than positive reserve provision, as wind turbines can use their full capacity if not activated and do not have to be curtailed ex ante. The participation of wind turbines especially reduces the occurrence of peak prices for positive and negative reserves in 2025 . This reduction effect occurs even with a relatively low share where wind turbines participate with only five percent of their capacity. Therefore, further fostering the process of allowing wind turbines to participate in the German reserve market seems favorable.
\end{abstract}

JEL Codes: Q42, Q47, Q48, C61, L94

Keywords: balancing reserves, electricity sector modeling, power plant dispatch, wind participation.

\footnotetext{
*clorenz@diw.de, German Institute for Economic Research (DIW Berlin), Department of Energy, Transportation, Environment, Mohrenstraße 58, 10117 Berlin.

${ }^{\dagger}$ Berlin University of Technology, Workgroup for Infrastructure Policy (WIP), Straße des 17. Juni 135, 10623 Berlin.
} 


\section{Introduction}

The degree of reliability of every electricity system depends on the functioning of all components and market segments. One of these markets is the balancing market and effective operation of balancing reserves to control short-term deviations of demand and supply is paramount. In this paper we analyze possible price and dispatch developments in the German balancing market until 2025. The application to Germany proves to be an interesting study topic, as the current market structure might change significantly in the future. The range of changes is manifold and includes adjustments to auction design, increased market harmonization with neighboring countries, transformation of the power plant portfolio and entrance of new market participants. We want to analyze the effects of the latter two.

In the context of the low carbon transformation of the electricity system, the share of renewables is expected to increase. The rising share of renewable energy sources (RES) could lead to a change in balancing reserve demand (see Section 3) but could also enable participation of renewables in the provision of balancing reserves, where (among other actors) fluctuating renewables will be able to offer a percentage of their output on the market.

The reasons for deviations from the alternating current (AC) system's nominal frequency of $50 \mathrm{~Hz}$ can be numerous: i) load fluctuates constantly and cannot be forecast perfectly, ii) schedule leaps occur between each auctioned (quarter) hour, iii) power plant or grid outages take place unexpectedly, and iv) the in-feed of RES deviates from its forecast. All these deviations alter the system's frequency, balancing reserves restore and stabilize the frequency by activating upward or downward reserves. The balancing market in Germany is organized in three products, distinguished by their response time and length of activation. In Germany these products are primary balancing power (PRL, Primärregelleistung), secondary balancing power (SRL, Sekundärregelleistung), and tertiary balancing power (TRL, Tertiärregelleistung), corresponding to the nomenclature primary control (PC), secondary control (SC), and tertiary control (TC) of this paper. ${ }^{1}$

The current state and development of the German balancing markets is discussed in general in Hirth and Ziegenhagen (2015), Koliou et al. (2014), Mauritzen (2015), and Müsgens et al. (2011). The majority of the literature focuses research questions ranging from technical balancing frameworks and the integration of renewables, the market design, or pricing policies. Methods of analysis are manifold, starting with numerical fundamental models (Chao and Wilson, 2002; Müsgens et al., 2014; Ortner and Graf, 2013; Swider, 2007). These models are often mixed integer

\footnotetext{
${ }^{1}$ These products are auctioned by the four German transmission system operators (TSOs) on a joint platform, where some pre-qualified units from outside of Germany are able to participate. The German TSOs are also part of the International Grid Control Cooperation (IGCC), which fosters cross-border balancing exchanges. Together with seven neighboring TSOs, imbalance netting of SC capacities is applied to reduce total activation volumes. Throughout the literature different terms like balancing reserves, balancing capacity, control power, control energy are used. We will use the terms balancing reserves, balancing power and balancing energy that are used by ENTSO-E (2013). The differentiation of the balancing power products used in this paper corresponds to the German variant. Thus, short-time load frequency control products such as frequency containment reserve (FCR) are PC, while automatic frequency restoration reserve (aFRR) is denoted as SC and manual frequency restoration reserve $(\mathrm{mFRR})$ is denoted as TC in this paper. Furthermore, replacement reserve (RR) are used to restore the required level of other reserves (FCR, aFRR, and mFRR) to be prepared for a further system imbalance. No comparable balancing product exists in Germany.
} 
linear programs (MILPs) with a detailed representation of power plant characteristics in the dispatch. Stochastic approaches are applied by Just (2011) and Lindsjørn (2012). The evaluation of statistical (panel-)data such as realized market outcomes and company behavior is conducted by Growitsch et al. (2010), Haucap et al. (2014), and Heim and Goetz (2013).

The auction design of balancing capacity reservation is often discussed: Abbasy et al. (2010), Bucksteeg et al. (2014), Knaut et al. (2017), Müsgens et al. (2012, 2014), Niesen and Weber (2014), and Swider (2007) discuss lead times in the balancing market and conclude that shorter lead times and increased flexibility of auctions in the balancing market also positively affect the efficiency of the spot market. Böttger and Bruckner (2015), Just and Weber (2008), and Just (2011) show that shorter contract duration lead to efficiency increases and less capacity effectively withheld from the spot market.

Furthermore, the effect of allowing new market participants other than conventional or renewable power plants such as renewables, battery storage, electrical boilers or managed refrigerated warehouses into the market is discussed. As discussed in Hirth and Ziegenhagen (2015) and Sorknæs et al. (2013), fluctuating renewables will most likely supply negative balancing in the next years. However, with increased hours of excess electricity production, it starts to makes sense for RES also to provide positive reserves. During these times, withholding generation from RES for balancing reserves leads to no system cost, as they would be curtailed in any case. The model used in Böttger and Bruckner (2015) is also used in Böttger et al. (2015) to analyze the participation of 1,000 MW of electric boilers on negative SC and show cost savings of about 52-158 million $€$ in Germany in 2025. The effect of participation of wind and solar photovoltaic (PV) on the German balancing market of 2035 is analyzed by Spieker et al. (2016) using a detailed fundamental unit-commitment model. Similar to the results obtained in this paper, the authors show that with participation of renewables, the total balancing reservation cost are decreased, but remain above 2014 values.

Increased cooperation between neighboring balancing markets regarding reservation and activation of SC and TC reserves between Austria, Germany and Switzerland is carried out in Lorenz and Gerbaulet (2014) with the result, that regional cooperation can significantly reduce total reserve provision costs. Similarly, Farahmand and Doorman (2012), Gebrekiros et al. (2013, 2015a,b), and Jaehnert and Doorman (2010) conclude that joint reserve provision in northern Europe is beneficial.

Possibly grouping bids into portfolios also affects the market outcome. Niesen and Weber (2014) formulate an analytical equilibrium model of the balancing market and show that capacity prices are lower with shorter contract durations using a detailed unit commitment model applied to the European electricity market of 2012. If large power plant portfolios are introduced into the market, this effect is reduced. These results are confirmed by Lorenz et al. (2014), who apply a unit-commitment model of the German balancing market that allows for portfolio bidding by large generation companies. 
Several of the changes to the current market setup suggested in the literature have been adopted by the European Network of Transmission System Operators for Electricity (ENTSO-E) and the European Commission (EC). In the current draft of the EC's regulation of establishing a guideline on electricity balancing (EC, 2017), measures such as the harmonization of the balancing products and changes to the gate closure times and pricing structures are addressed, which could further improve the efficiency of the market and enable more flexibility in providing balancing services by wind turbines and other market participants.

This paper contributes to the existing literature by introducing the fundamental unit commitment model ELMOD-MIP, which features a novel approach of modeling balancing reserve provision by considering possible activation costs during the reservation phase. The anticipation of reserve activation probabilities, should lead to a more realistic balancing reserve dispatch. We use this model to give an outlook on the developments of the German balancing market until 2025 and analyze the influence of wind turbines participating in the provisioning of balancing reserves. The paper is structured as follows: Section 2 describes the characteristics and motivation of ELMOD-MIP, as well as the applied novel approach of our methodology and fundamental price formations in the balancing market. The mathematical formulation of the model is presented in Section 2.1. In Section 3 the data and scenarios applied to ELMOD-MIP are described. The results are analyzed in Section 4 and followed by a conclusion in Section 5 .

\section{Methodology}

In order to be able to analyze possible changes in the balancing reserve markets, the basis is an accurate representation of the power plant dispatch in the respective market area, as the balancing reserve market is a comparatively small part of the entire electricity sector. The goal is to find an approximation of the prices, quantities and cost that the balancing market could have under the assumption of a perfectly competitive market setup without any inefficiencies and strategic behavior. We focus on secondary and tertiary control reserves and neglect primary control reserves due to comparable small market volumes and complex technical prerequisites for its provision.

In fundamental optimization models, the procurement of balancing reserves is often represented using one or more market clearing equations, that represent the balancing reservation demand and is fulfilled by the market participants by reserving a part of their upward or downward generation potential. This influences the dispatch decision, as the flexibility to operate on the "main" market is restricted by the balancing reservation. Further, the model's selection of what type of generation capacity or power plant is used to provide balancing services is largely influenced by the models' level of detail. This approach can be applied in linear models (Jaehnert and Doorman, 2010; Zerrahn and Schill, 2015) on a technological or block-sharp level, as well as unit commitment models. These models implement more complex power plant dispatch restrictions such as start-up cost, minimum load, or minimum offline or online durations (van den Bergh 
et al., 2016; Böttger et al., 2015; Brouwer et al., 2014; Farahmand et al., 2012). The impact of power plants' part-load behavior further influences the model outcome, as especially to be able to provide positive balancing reserves, some upward potential needs to be kept available, leading to a dispatch below the optimum efficiency point. In Bucksteeg et al. (2014) and Knaut et al. (2017) this characteristic is also reflected in the balancing reserves procurement. To further improve the model's selection of capacities for balancing reserves during the balancing reservation phase Gebrekiros et al. (2015b) and Müsgens et al. (2012) include an approximation of opportunity cost between the balancing and spot markets commitment.

Most approaches presented do not anticipate the activation of balancing reserves during the reservation phase, or use static approaches to weigh the decision what capacities should provide balancing services. The approach used this paper contributes to the literature by presenting an endogenous anticipation of the balancing reserves' activation probability. To represent the market participant's assumptions over the different stages of the balancing market (capacity reservation and energy activation) ELMOD-MIP has the possibility to anticipate the probability of balancing reserve activations during the reservation phase. This anticipation of the activation probability has several advantages: It resembles the behavior that is expected from real market participants, that are likely to include the revenue from the activations in their market participation. In ELMOD-MIP, this leads a more realistic and slightly higher balancing reserve cost estimation than a negligence of the activation probabilities.

ELMOD-MIP is a bottom-up electricity sector model, formulated as a MILP which allows us to include unit-commitment constraints as minimum load, part-load efficiency, time-dependent start-up and shutdown restrictions, complex combined heat and power (CHP) constraints and minimum bid sizes for balancing capacity reservation. These detailed representations of the power plants' flexibility are crucial to accurately represent the power plant dispatch as well as capacity reservation when modeling balancing markets. If these constraints were not part of the model, the power plants' flexibility would be significantly overestimated and distort the balancing market outcome.

\subsection{The model ELMOD-MIP}

We formulate ELMOD-MIP as a multi-step approach (Figure 1), where for all steps the same model is used, but some equations are deactivated and some variables and parameters are fixed or set to zero based on each step's goal.

In the first step, the spot and balancing reserve markets are optimized simultaneously, minimizing total system cost. Thus, the balancing capacity reservation as well as the power plant dispatch in the spot market are determined. The actual balancing reserve activations are not part of the optimization, as they are approximated using the anticipated reserve activation probability, or neglected depending on the scenario (see Section 3).

In the second step, the activation of balancing reserve is optimized. Necessary activated balancing reserve is determined based on historical time series. Here, the variables determining 


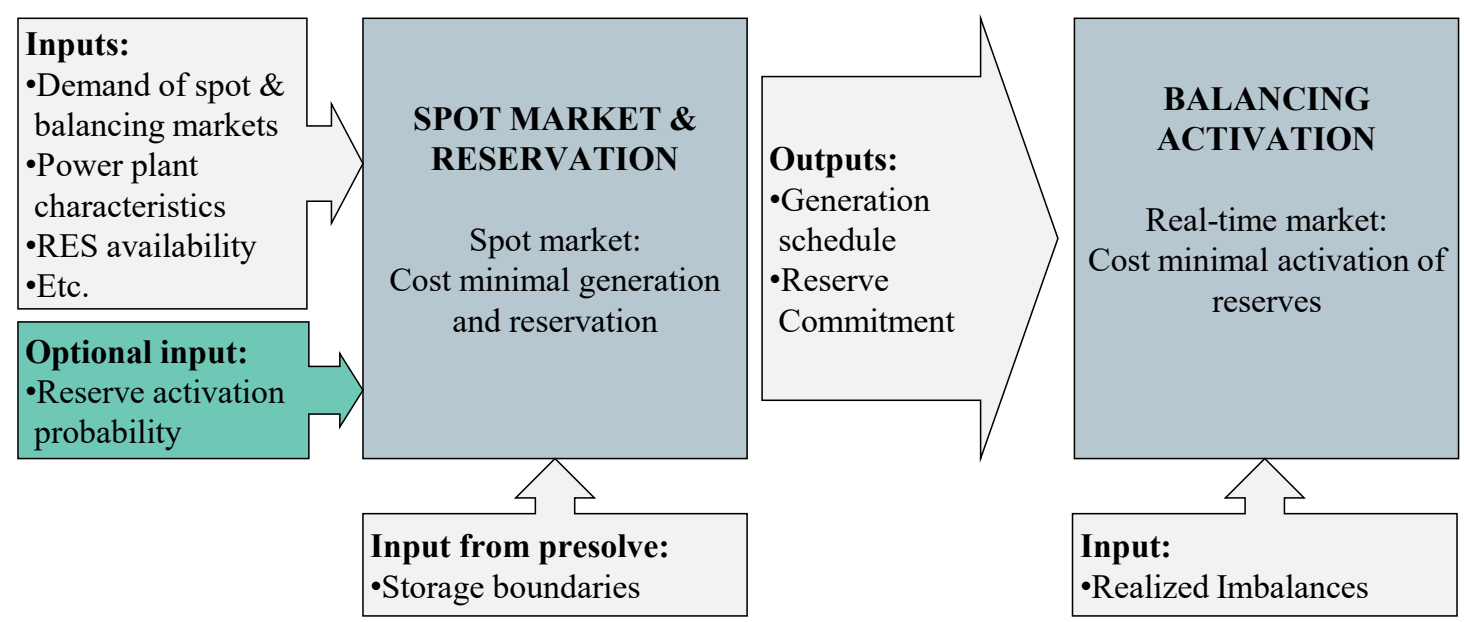

Figure 1: ELMOD-MIP Model Steps

the reservation of balancing capacity are fixed in the model. Only power plants with reserved capacity can be dispatched for balancing reserve activations by the model.

To generate storage levels and associated limitations for the starting and end period of each individual week, we solve a limited version of the model ("presolve") for the entire model year prior to the actual calculations using the same input data. The limited version is a linear reformulation with technology sharp aggregation for non-hydro generation and linear balancing requirements.

In this paper we focus on the cost induced by the balancing reserves' influence on the electricity system as generation technologies reserve capacity to provide them. Hence, the cost for activating these reserves is not fully analyzed in this paper. Still, balancing reserve activation is fully implemented in the model and the calculations. This is necessary as the activation results in additional technical constraints for the reservation phase. Furthermore, this allows us to study possible impacts on activation cost in subsequent analyses. The cost for balancing activation will therefore only be evaluated briefly.

\subsection{Determining the cost of balancing reserves}

Determining cost and prices for balancing reserve provision in fundamental electricity system models can be a challenge. In contrast to the spot market, balancing reserve cost comprise of different components. Furthermore, the total balancing reserve cost can not be quantified directly, as it is influenced by the spot market situation.

\subsubsection{Balancing cost components}

In ELMOD-MIP, three factors can induce costs when reserving balancing capacity: Opportunity costs, part-load costs when reserving positive balancing capacity, and the cost of anticipated balancing reserve activation. 
First, opportunity costs occur in the spot market due to balancing restrictions on the available generation capacity. Capacity is either reserved in a power plant in case of positive capacity reservation, or a must-run condition is introduced in case of negative capacity reservation. Depending on the difference between current market price and the marginal cost of the power plant opportunity cost are described in (1) and (2).

$$
\begin{aligned}
\operatorname{cost}_{p}^{r e s v, p o s} & = \begin{cases}\left(p^{\text {spot }}-m c_{p}\right) \cdot G_{p, t}^{r e s v, p o s} & \text { if } p^{\text {spot }} \geq m c_{p} \\
\left(m c_{p}-p^{s p o t}\right) \cdot g_{p}^{\text {min }} \cdot g_{p}^{\text {max }} & \text { if } p^{\text {spot }} \leq m c_{p}\end{cases} \\
\text { cost }_{p}^{\text {resv }, \text { neg }} & = \begin{cases}0 & \text { if } p^{\text {spot }} \geq m c_{p} \\
\left(m c_{p}-p^{s p o t}\right) \cdot g_{p}^{\text {min }} \cdot g_{p}^{\text {max }}+G_{p, t}^{\text {resv }, \text { neg }} & \text { if } p^{\text {spot }} \leq m c_{p}\end{cases}
\end{aligned}
$$

The opportunity cost for positive reservation are zero if the marginal cost of the power plant equal the current market price. Hence, the price setting power plant can theoretically provide reserves without opportunity cost. Power plants without minimum load constraints, such as pumped hydro or run-of-river power plants (RoR) are able to provide positive reserves at no cost, as long as their water value is above the spot market price. If the water value is lower than the spot market price, opportunity costs occur. Inflexible CHP plants without a heat storage (or other means to provide heat output) also have no opportunity cost for capacity reservation, at times when their marginal costs are above the spot market price but they have to produce heat and therefore need to run at least at minimum load. In this situation they do not face any losses from not offering their spare capacity at the spot market and therefore can provide reserves at no opportunity cost.

Opportunity cost are zero for negative reserves, if the power plants' marginal cost are below the market price and the power plant is producing for the spot market. Hence, as long as a power plants is "in the money," it can provide negative reserves at zero cost. A detailed explanation and more examples can be found in Müsgens et al. (2014) and Brandstätt (2014).

Second, in the case of positive reserve provision, power plants have to produce below their rated capacity and thus are not able to operate at their optimal output point. This results in higher relative fuel cost for electricity production as the power plant's efficiency is reduced. These part-load cost are the biggest cost component when power plants marginal cost are close or equal to the spot price.

The third cost component is the anticipated balancing reserve activation. As the activation probability distribution can be anticipated in ELMOD-MIP (see Section 2.3 below), the activation probability of balancing reserves takes into account the cost for additional fuel or startup costs that occur when activated. This also includes anticipated part-load situations when deviations from the optimal power plant dispatch are anticipated. 


\subsubsection{Balancing cost calculation}

In this paper the cost of balancing reservation is calculated as the difference in system cost, with and without balancing reserve restrictions. Van den Bergh et al. (2016), Gebrekiros et al. (2015b), and Knaut et al. (2017) use a two-step approach that is also used in this paper. In a first calculation, the amount of balancing capacity reserved is set to zero, and all power plant capacities can operate fully on the spot market. This is compared to the actual calculations with balancing reservation. The increase in cost contains all alterations occurring in the spot market, such as a selection of more costly power plants in the dispatch, as well as part-load costs of power plants that provide positive balancing reserves.

Brandstätt (2014) and Müsgens et al. (2012) estimate the opportunity cost of providing balancing reserves for each power plant in a first step. Based on these cost, they determine which power plants are the cheapest to provide reserves. The product of these cost with the actually reserved capacity gives the total cost of balancing reservation. This approach allows for a plant-sharp estimation of balancing reservation cost, but has the disadvantage of neglecting some aspects of interaction between the spot and balancing markets. Especially the effect of part-load efficiency decrease of the power plants induced by the reservation is neglected, which is a main cost-driver of balancing reserve provision (see above). Thus not all system cost components that arise from balancing reservation are reflected.

\subsection{Anticipating balancing reserve activations}

To be able to incorporate the uncertainty of how much balancing power is actually activated, we separate the balancing reserves into multiple products with different sizes and activation probabilities. This methodology approximates the actual activation distribution, where a small amount of balancing reserves is almost always activated, but the maximum reserved capacity is activated only in a few hours per year. The model uses this information to determine which power plants are likely to be used for the activation of balancing reserves by taking into account the activation cost multiplied by the activation probability. This becomes part of the optimization. Thus, power plants are not just committed to provide balancing capacity, but are committed to a small block of balancing capacity with a certain activation probability. Assigning multiple blocks and splitting each block's capacity to multiple power plants is possible. The effect of this improvement is analyzed in the 2013 Anticipation scenario (see Section 3).

Historical frequencies for SC are shown in Figure 2. We derive the distribution of these blocks using historical time series data that are part of the model input described in section 3 . The sum of each block's size in megawatt (MW) multiplied by the frequency equals the average activation values in MW. This ensures that the model's anticipation of the average balancing reserve activations is correct.

In the current market design, balancing capacity is reserved regularly for time periods between four hours and one week, depending on the product and region. This reservation is allocated to 


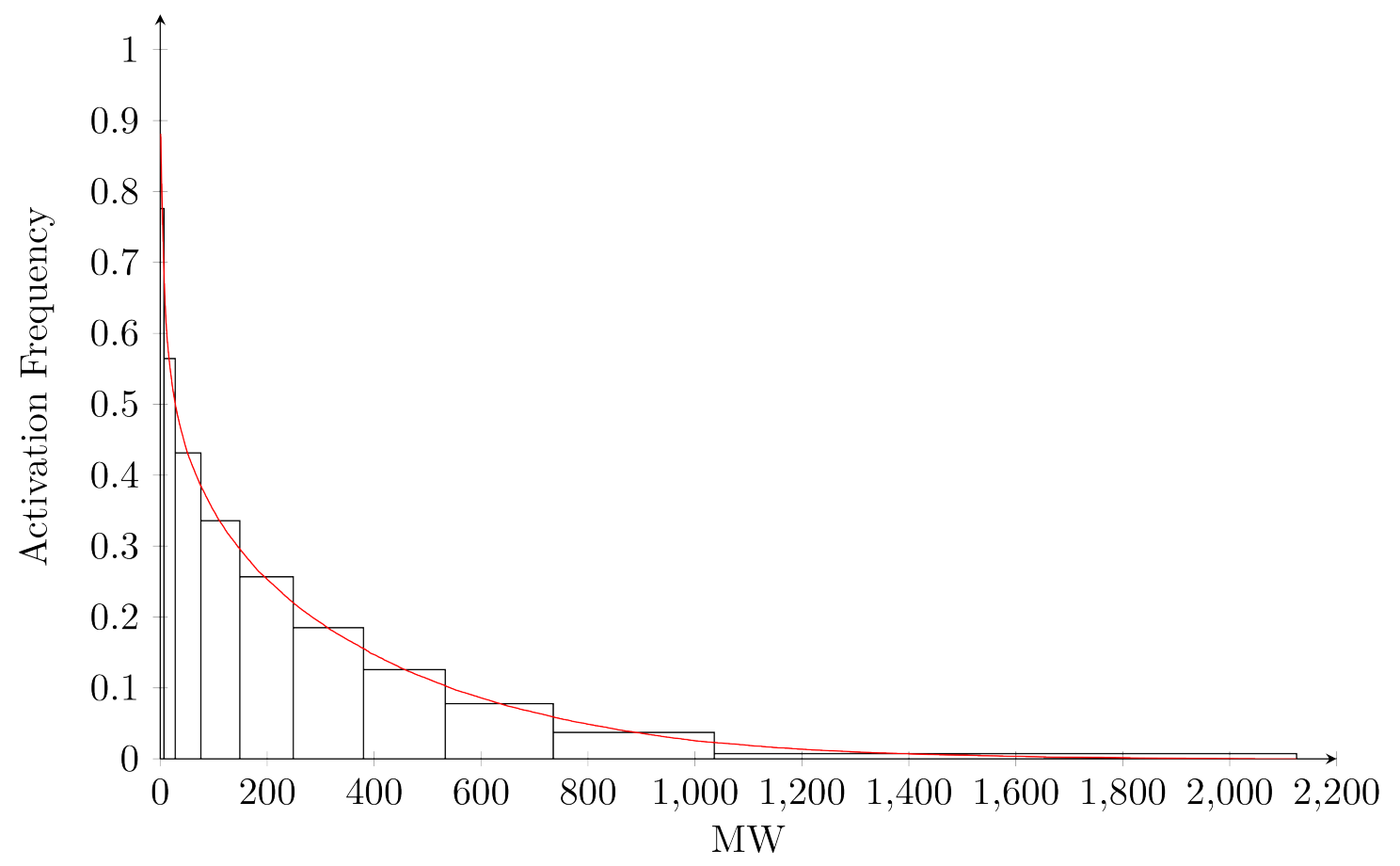

Figure 2: Activation frequency for positive SC in Germany 2013 and calculated blocks.

the bidding firm's power plant portfolio and not to individual plants. Therefore, the firms can optimize their power plant portfolio at the time of delivery of the balancing energy, hence at least hourly. In ELMOD-MIP we approximate this setting by allowing for balancing capacity reservation for each power plant and hour separately. This results in a situation similar to various big firms participating in a cost minimizing behavior on the balancing market.

We do not apply price markups for balancing capacity because they might distort the model results significantly in case of changing market situations (induced by increased cooperation or a changed future power plant portfolio), as the markups are usually not endogenous to the model and based on historical data. This approach gives us the possibility to determine a lower bound of the anticipated balancing cost for the future electricity system.

\subsection{Computational complexity}

The problem is solved in 52 weekly blocks with two days overlap ${ }^{2}$ to cover a whole year. This allows us to parallelize the calculations and reduce the computation time for an entire year significantly. It is solved with the help of a unix cluster. Up to 50 nodes were used in parallel, each equipped with at least $16 \mathrm{~GB}$ of RAM and AMD or Intel processors of at least $2.6 \mathrm{GHz}$. For the scenarios without anticipation, each calculation period needs up to 20 hours. Thanks to

\footnotetext{
${ }^{2}$ See Barrows et al. (2014) for an analysis of time series partitioning and overlap times. The authors suggest the setting used in this paper to achieve adequate solutions while achieving fast solution times.
} 
parallelization each scenario can be calculated in less than two days. However, the scenarios with anticipation need up to one week of wall-clock time as each calculation period can take up to 100 hours.

\subsection{Mathematical formulation}

The objective of ELMOD-MIP is to minimize total system costs, while clearing the spot market as well as the balancing market for the two balancing power products SC and TC. The model is solved using the General Algebraic Modeling System (GAMS) with the commercial solver CPLEX.

The mathematical formulation can be found in equations (3) to (53). The overall objective is to minimize the sum of generation, start-up, shut-down, and balancing cost $(3-10)$. For the scenarios where no anticipation of activations is included, the parameter $f r q_{b l, b}$ is set to zero and equations are simplified.

$$
\begin{aligned}
\min \text { Cost }^{\text {total }}= & \text { Cost }^{\text {gen }}+\text { Cost }^{\text {start }}+\text { Cost }^{\text {down }}+\text { Cost }^{\text {ramp }} \\
& + \text { Cost }^{\text {partload }}+\text { Cost }^{\text {resv }}+\text { Cost }^{\text {call }}
\end{aligned}
$$

s.t.

$$
\begin{aligned}
& \operatorname{Cost}^{\text {gen }}=\sum_{c, t} m c_{c} \cdot G_{c, t} \\
& \text { Cost }^{\text {start }}=\sum_{c, t} U P_{c, t} \cdot c_{c}^{\text {start }}+\sum_{u, t} F r q_{u, t}^{\max } \cdot c_{u}^{\text {start }} \\
& \operatorname{Cost}^{\text {down }}=\sum_{c, t} D N_{c, t} \cdot c_{c}^{\text {down }}+\sum_{u, t} F r q_{u, t}^{\max } \cdot c_{u}^{\text {down }} \\
& \operatorname{Cost}^{\text {ramp }}=\sum_{p, t} G_{p, t}^{\text {rampup }} \cdot c_{c}^{\text {rampup }}+G_{p, t}^{\text {rampdown }} \cdot c_{c}^{\text {rampdown }} \\
& \text { Cost }^{\text {partload }}=\sum_{c, t} O N_{c, t} \cdot c_{c}^{\text {partload }}-\frac{c_{c}^{\text {partload }}}{g_{c}^{\text {max }} \cdot a v a_{c, t}-g_{c}^{\text {min }} \cdot g_{c}^{\text {max }}} \cdot\left(G_{c, t}\right. \\
& -g_{c}^{\text {min }} \cdot g_{c}^{\text {max }}+\sum_{b}\left(G_{b, c, t}^{\text {call,pos }}-G_{b, c, t}^{\text {call, neg }}+\sum_{b l}\left(\left(G_{u \in c, t, b l, b}^{\text {resv } p o s}\right.\right.\right. \\
& \left.\left.\left.\left.-G_{u \in c, t, b l, b}^{r e s v, n g}\right) \cdot f r q_{b l, b}\right)\right)\right) \\
& \operatorname{Cost}^{r e s v}=\sum_{b, b l, c, t} m c_{c} \cdot\left(G_{c, t, b l, b}^{r e s v, p o s}-G_{c, t, b l, b}^{r e s v, n e g}\right) \cdot f r q_{b l, b} \\
& \operatorname{Cost}^{\text {call }}=\sum_{b, c, t} m c_{c} \cdot\left(G_{b, c, t}^{\text {call,pos }}-G_{b, c, t}^{\text {call,neg }}\right)
\end{aligned}
$$

The total system costs (3) include variable costs of generation (4), start-up (5) and shut-down (6) costs, ramping cost (7), part-load cost (8) and the costs for providing balancing power (9) 
and (10). The variable cost of generation is defined as the generation $G_{c, t}$ of all conventional power plants $c$ and time steps $t$ multiplied by the plants' marginal production cost $m c_{c}$. Start-up $\operatorname{cost} c_{c}^{\text {start }}$ occur when a plant assumes production and was in a shut-down state in the previous time step. Then, the binary variable $U P_{c, t}$ has the value 1.

During the reservation phase the expected start up probability of fast-starting power plants $u$, which is a subset of all conventional power plants $c$, is also taken into account. Shut-down cost occur analogously. For fast-starting power plants that do not participate in the spot market at the time of activation, we assume that these plants provide balancing power for a short time period and shut down afterward. Therefore not only the startup cost $c_{u}^{\text {start }}$ but also the shut-down cost $c_{u}^{\text {down }}$ are taken into account as well during the reservation phase.

The reservation of positive or negative balancing capacity $G_{c, t, b l, b}^{r e s v, p o s}$ and $G_{c, t, b l, b}^{r e s v, n e g}$ for the balancing power products $b$ and blocks $b l$ incurs opportunity cost $m c_{c}$ multiplied with the block's specific activation frequency $f r q_{b l, b}$ in the model, as the capacity reservation reduces the available capacity in the spot markets. The balancing reserve activations $G_{b, c, t}^{c a l l, p o s}$ and $G_{b, c, t}^{c a l l, n e g}$ are accounted for by the power plants' marginal cost $m c_{c}$. The part-load cost represent the non-linear link between fuel cost per produced MWh depending on current output level. At minimum generation level, part load cost in the magnitude of $c_{c}^{\text {partload }}$ would occur. When a power plant is operating above minimum generation level, these costs are reduced depending on current output level $G_{c, t}$ as expressed in the fraction. ${ }^{3}$

\subsubsection{Market clearing}

The spot market is cleared by leveling load $q_{r, t}^{\text {spot}}$, dispatchable generation $G_{c, t}$, storage activity $G_{s, t}^{u p}, G_{s, t}^{\text {down }}$, non-dispatchable renewable and conventional feed-in $g_{r, t}^{r e s}, g_{r, t}^{c o n v}$, and exogenous exchange flows $g^{c b}$ for all time steps $t$ and regions $r$, as stated in (11). Markets for positive and negative balancing capacity are cleared separately for each product $b$ and block $b l$, by leveling demand $q_{b, b l, r, t}^{r e s v, p o s}, q_{b, b l, r, t}^{r e s v, n e g}$ and reserves $G_{p, t, b l, b}^{r e s v}, G_{p, t, b l, b}^{r e s v, n e g}$. This is shown in (12) and (13) for the reservation and in (14) and (15) for the activation of balancing reserve.

$$
\begin{array}{rlr}
0= & q_{r, t}^{\text {spot }}-\sum_{c \in r} G_{c, t}+\sum_{s}\left(G_{s, t}^{\text {up }}-G_{s, t}^{\text {down }}\right) & \\
& -g_{r, t}^{r e s}-g_{r, t}^{c o n v}-g_{r, t}^{c b} & \\
q_{b, b l, r, t}^{r e s v, p o s}= & \sum_{p \in r} G_{p, t, b l, b}^{r e s v, p o s} & \forall t, r, b l, b \\
q_{b, b l, r, t}^{r e s v, \text { neg }}= & \sum_{p \in r} G_{p, t, b l, b}^{r e s v, n e g} & \forall t, r, b l, b \\
q_{b, r, t}^{\text {call,pos }}= & \sum_{p \in r} G_{b, p, t}^{\text {call,pos }} & \forall b, r, t
\end{array}
$$

\footnotetext{
${ }^{3}$ The combination of equations (4) and (8) replicates the part-load decrease of a power plant's efficiency $\eta$ using the formula $\eta(G)=\frac{G}{a G+b}$ where $G \in\left[g^{\text {min }}, g^{\text {max }}\right] . a$ and $b$ are power plant specific parameters, $g^{\text {min }}$ and $g^{\max }$ are minimum and full power plant output.
} 


$$
q_{b, r, t}^{\text {call,neg }}=\sum_{p \in r} G_{b, p, t}^{c a l l, \text { neg }} \quad \forall b, r, t
$$

\subsubsection{Generation restrictions}

$$
\begin{aligned}
& G_{c, t} \leq g_{c}^{\text {max }} \cdot a v a_{c, t}-\sum_{b l, b} G_{c, t, b l, b}^{r e s v, p o s} \quad \forall c, t \\
& G_{c, t} \geq g_{c}^{\min } \cdot g_{c}^{\max } \cdot O N_{c, t}+\sum_{b l, b} G_{c, t, b l, b}^{r e s v, n e g} \quad \forall c, t \\
& G_{o, t} \leq O N_{o, t} \cdot g_{o}^{\max } \cdot a v a_{o, t}-\sum_{b l, b} G_{o, t, b l, b}^{r e s v, p o s} \quad \forall o, t \\
& G_{u, t} \leq O N_{u, t} \cdot g_{u}^{\max } \cdot a v a_{u, t}-\sum_{b l} G_{u, t, b l, s c}^{r e s v, p o s} \quad \forall u, t \\
& D N_{c, t}+O N_{c, t}=U P_{c, t}+O N_{c, t-1} \quad \forall c, t \\
& U P_{c, t}+D N_{c, t} \leq 1 \quad \forall c, t \\
& 1-U P_{c, t-t_{c}^{\text {minup }}} \geq \sum_{\text {minup }}^{t} D N_{c, t t} \quad \forall c, t \\
& 1-D N_{c, t-t_{c}^{\operatorname{mindn}}} \geq \sum^{t} U P_{c, t t} \quad \forall c, t \\
& G_{c, t} \geq \sum_{b, b l} G_{b, b l, c, t}^{r e s v, n e g} \quad \forall c, t \\
& G_{t c, b l, u, t}^{\text {resv }, \text { pos }} \leq\left(S B_{b, b l, u, t}+O N_{u, t}\right) \cdot g_{u}^{\max } \quad \forall t c, b l, u, t \\
& G_{t c, b l, u, t}^{\text {resv,pos }} \geq S B_{b, b l, u, t} \cdot g_{u}^{\max } \cdot g_{u}^{\min } \quad \forall t c, b l, u, t \\
& F r q_{u, t}^{\max } \geq S B_{b, b l, u, t} \cdot f r q_{b, b l} \quad \forall b, b l, u, t \\
& 1 \geq S B_{b, b l, u, t}+O N_{u, t} \quad \forall b, b l, u, t
\end{aligned}
$$

A power plant's generation $G_{c, t}$ and balancing reservation $G_{c, t, b l, b}^{r e s v, p o s}, G_{c, t, b l, b}^{r e s v e g}$ are constrained by its minimal and maximal generation capacity (16), (17). Slow starting power plants $o$ have to be online to provide balancing power (18) while fast starting power plants $u$ must only be online when providing energy for the spot market (19) and can be on stand-by to provide reserves (25). In case of activation of reserve energy we assume that these power plants can reach the desired output levels within time from a shutdown state. Equation (20) tracks the plant's status for start-up and shut-down costs and enforces the plant to start up when providing balancing power. Power plants are further restricted by minimum online and offline times. If a plant was started up it cannot be shut down within the interval $t_{c, t}^{\text {minup }}$ and vice versa for start ups after a shut down as shown in (22) and (23). The amount of negative reserved balancing power must always be smaller that the spot market generation of the power plant (24). This enforces power plants to be online and to participate in the spot market in order to provide negative balancing power. Slow 
starting power plants $o$ must be online to provide positive balancing power as well (18), whereas fast starting power plants $u$ can be in standby mode (25). Fast starting power plants must bid at least their $g^{\text {min }}$ when they are bidding out of a standby status (26). Fast starting plants that are not generating but provide balancing power will incur their start-up and shut-down costs according to their expected activation frequency (27). Equation (28) ensures that plants can only either be online or in standby mode.

\subsubsection{Combined heat and power}

Power plants that additionally deliver heat to industrial or residential customers are further restricted in their operation by the equations (29) to (33). We separate the CHP plants into plants with a heat storage chps and plants without the possibility to store heat chpn. The heat storage level $C h p_{\text {chps,t }}^{\text {storagelevel }}$ is defined in equation (30) as the level from the previous hour times an heat loss factor plus heat generation by the power plant $C h p_{c h p s, t}^{\text {output }}$ and minus the heat that is consumed by industry or households. The heat generation is limited in (29) not to be higher than the current generation level. The heat level and output are measured in MWh electrical energy but not thermal energy, as the heat demand is also specified as a minimum electricity generation.

$$
\begin{aligned}
& C h p_{\text {chps }, t}^{\text {output }} \leq G_{\text {chps }, t} \quad \forall \text { chps }, t \\
& C h p_{\text {chps }, t}^{\text {storagelevel }}=C h p_{\text {chps }, t-1}^{\text {storagelevel }} \cdot \text { eta }^{\text {chp }} \quad \forall \text { chps }, t \\
& C h p_{\text {chps }, t}^{\text {storagelevel }} \leq \text { chp } p_{\text {chp }}^{\text {storagemax }} \quad \forall \text { chps }, t \\
& G_{c h p n, t}+\sum_{b l, b} G_{c h p n, t, b l, b}^{r e s v, p o s} \leq g_{c h p, t}^{\max , c h p} \cdot g_{\text {chpn }, t}^{\max } \quad \forall \text { chpn }, t \\
& G_{c h p n, t}-\sum_{b l, b} G_{c h p n, t, b l, b}^{r e s v, n e g} \geq g_{c h p, t}^{\min , c h p} \cdot g_{c h p n, t}^{\max } \quad \forall \operatorname{chpn}, t
\end{aligned}
$$

Power plants without heat storage are constraint by equations (32) and (33). In contrast they have to produce the heat at the specific hour it is needed. The parameters $g_{c h p, t}^{\max , \operatorname{ch} p}$ and $g_{c h p, t}^{\min , \operatorname{ch} p}$ are determined based on power plant characteristics and an exemplary heat demand curves dependent on outside temperature and hour of the day.

\subsubsection{Ramping}

$$
\begin{array}{rlrl}
G_{c, t}^{\text {rampup }} & \leq r_{c}^{u p} \cdot g_{c}^{\text {max }}+\sum_{b l, b} G_{c, t-1, b l, b}^{\text {resv,neg}}-\sum_{b l, b} G_{c, t, b l, b}^{\text {resv,pos }} & & \forall c, t \\
G_{c, t}^{\text {rampdown }} & \leq r_{c}^{\text {down }} \cdot g_{c}^{\text {max }}+\sum_{b l, b} G_{c, t, b l, b}^{r e s v, n e g}-\sum_{b l, b} G_{c, t-1, b l, b}^{r e s v, p o s} & \forall c, t
\end{array}
$$




$$
\begin{aligned}
G_{c, t}-G_{c, t-1} & +\sum_{b l, b}\left(G_{c, t, b l, b}^{r e s v, p o s}-G_{c, t-1, b l, b}^{r e s v, p o s}\right) \cdot f r q_{b l, b} \\
& -\sum_{b l, b}\left(G_{c, t, b l, b}^{r e s v, n e g}-G_{c, t-1, b l, b}^{r e s v, n e g}\right) \cdot f r q_{b l, b} \\
& +\sum_{b}\left(G_{b, c, t}^{c a l l, p o s}-G_{b, c, t-1}^{\text {call,pos}}\right)-\left(G_{b, c, t}^{\text {call }, \text { neg }}-G_{b, c, t-1}^{\text {call }, \text { eg }}\right) \\
& =G_{c, t}^{\text {rampup }}-G_{c, t}^{\text {rampdown }}
\end{aligned} \quad \forall c, t
$$

The power plants' ramping restrictions are included in (34) and (35). These equations limit the change of a power plant's production levels between time steps. For ramping, only the limiting balancing reservations are included, as otherwise the model would be able to weaken the ramping restrictions by reserving balancing capacity in the reverse direction.

\subsubsection{Reserve restrictions}

$$
\begin{aligned}
& \sum_{b l} G_{b, b l, p, t}^{r e s v, p o s} \geq r e s v_{b}^{\text {min }} \cdot B A L_{b, p, t}^{\text {pos }} \quad \forall b, p, t \\
& \sum_{b l} G_{b, b l, p, t}^{r e s v, n e g} \geq \operatorname{resv}_{b}^{\text {min }} \cdot B A L_{b, p, t}^{n e g} \quad \forall b, p, t \\
& \sum_{b l} G_{b, b l, s, t}^{r e s v, p o s} \leq v_{s}^{\max } \cdot B A L_{b, s, t}^{\text {pos }} \quad \forall b, c, t \\
& \sum_{b l} G_{b, b l, s, t}^{r e s v, n e g} \leq w_{s}^{\max } \cdot B A L_{b, s, t}^{n e g} \quad \forall b, c, t \\
& \sum_{b l} G_{s c, b l, c, t}^{r e s v, p o s} \leq g_{c}^{\max } \cdot r_{c}^{u p} \cdot B A L_{s c, c, t}^{p o s} \cdot 5 \quad \forall c, t \\
& \sum_{b l} G_{t c, b l, c, t}^{r e s v} \leq g_{c}^{\max } \cdot r_{c}^{u p} \cdot B A L_{t c, c, t}^{p o s} \cdot 15-\sum_{b, b l} G_{s c, b l, c, t}^{r e s v, p o s} \quad \forall c, t \\
& \sum_{b l} G_{s c, b l, c, t}^{r e s v, n e g} \leq g_{c}^{\text {max }} \cdot r_{c}^{d o w n} \cdot B A L_{s c, c, t}^{n e g} \cdot 5 \quad \forall c, t \\
& \sum_{b l} G_{t c, b l, c, t}^{r e s v, n e g} \leq g_{c}^{\max } \cdot r_{c}^{d o w n} \cdot B A L_{t c, c, t}^{n e g} \cdot 15-\sum_{b, b l} G_{s c, b l, c, t}^{r e s v, n e g} \quad \forall c, t
\end{aligned}
$$

Equations (37) to (44) describe the restrictions that determine how much of a plant's capacity can be reserved for balancing. The combination of (37) and (38) enforces power plants or storages to bid at least the minimum bid specified by resv $_{b}^{\text {min }}$ when bidding into the balancing market. Storage plants can (besides other restrictions) only reserve as much capacity as limited by their pumping and generating abilities as seen in (39) to (40). Equations (41) and (44) limit the maximal bid size dependent on the maximum up and down ramping abilities of each power plant. 


\subsubsection{Activation restrictions}

$$
\begin{array}{rlrl}
G_{b, p, t}^{\text {call,pos }} & \leq \sum_{b l} G_{b, b l, p, t}^{\text {resv }} & & \forall b, p, t \\
G_{b, p, t}^{\text {call,neg }} & \leq \sum_{b l} G_{b, b l, p, t}^{r e s v, n e g} & \forall b, p, t \\
\sum_{b} G_{b, u, t}^{\text {call,pos}} & \leq g_{u}^{\max } \cdot O N_{u, t} & \forall u, t
\end{array}
$$

When reserve energy is activated, the positive and negative activation must always be smaller than the reserved amount for each power plant, hour and product as shown in (45) and (46). Equation (47) ensures that fast starting plants must start up to provide balancing energy. Note that the status of the power plants is not transferred between the stages of the multi-stage model but redetermined each stage, transferring the amount of reserved capacity is sufficient to determine the power plant status. A fast-starting power plant that is in "Standby" in the reservation stage with reserved capacity might be set to "Online" during the activation stage. This way the actual startup cost of fast starting power plants can be accounted for in the model when the activations take place.

\subsubsection{Storage restrictions}

$$
\begin{aligned}
& S T O R_{s, t}^{L}-S T O R_{s, t-1}^{L}=G_{s, t}^{u p} \cdot \eta_{s}-G_{s, t}^{\text {down }}+g_{s, t}^{\text {nat }}-G_{s, t}^{\text {discard }} \\
& -\sum_{b} G_{b, s, t}^{\text {call,pos }}+\sum_{b} G_{b, s, t}^{\text {Call, Neg }} \cdot \eta_{s} \quad \forall s, t \\
& v_{s}^{\text {max }} \geq G_{s, t}^{\text {down }}+\sum_{b l, b} G_{s, t, b l, b}^{\text {resv,pos }} \quad \forall s, t \\
& w_{s}^{\max } \geq G_{s, t}^{u p}+\sum_{b l, b} G_{s, t, b l, b}^{r e s v, n e g} \cdot \eta_{s} \quad \forall s, t \\
& S T O R_{s, t}^{L}-\sum_{b l, b, t t=t-12}^{t t=t+12} G_{s, t t, b l, b}^{r e s v, p o s} \cdot \eta_{s} \geq l_{s}^{\text {min }} \quad \forall s, t \\
& \operatorname{STOR}_{s, t}^{L}+\sum_{b l, b, t t=t-12}^{t t=t+12} G_{s, t t, b l, b}^{r e s v, n e g} \leq l_{s}^{\max } \quad \forall s, t
\end{aligned}
$$

In our model pumped hydro storage plants $s$ take part in the balancing market. Equation (48) describes the storage level $S T O R_{s, t}^{L}$ for every storage plant $s$ that is dependent on the historic storage level $S T O R_{s, t-1}^{L}$, pumping $G_{s, t}^{u p}$ and generation activities $G_{s, t}^{\text {down }}$. Equations (49) to (52) limit the pumping, generation, and storage level as well as reserved balancing power. The restrictions on minimum and maximum storage level include the reserved positive and negative balancing reserves twelve hours prior and post the actual time step. This should represent the constraint that, within a time interval of 24 hours, the storage contains a sufficient amount of 
water to be able to deliver the balancing energy for both extreme cases of no or full activations of balancing reserves in all 24 hours.

\subsubsection{Further restrictions}

$$
\begin{aligned}
G_{p, t}, G_{p, t}^{\text {rampup }}, G_{p, t}^{\text {rampdown }}, G_{s, t}^{u p}, G_{s, t}^{\text {down }}, S T O R_{s, t}^{L} & \geq 0 \\
G_{b, b l, c, t}^{\text {ResvPos }}, G_{b, b l, c, t}^{\text {ResvNeg }}, G_{b, p, t}^{\text {Call,Pos }}, G_{b, p, t}^{\text {Call,Neg }}, F r q_{u, t}^{\text {max }} & \geq 0 \\
C h p_{\text {chps }, t}^{\text {storagelevel }}, C h p_{\text {chps }, t}^{\text {output }} & \geq 0
\end{aligned} \quad \forall b, b l, p, t
$$

The constraints in (53) ensure positive values for some variables in the model.

\section{Scenarios and data}

We apply ELMOD-MIP to scenarios that represent the spot and balancing markets of Germany in 2013 and 2025. We use the year 2013 to estimate the effect of a potentially improved anticipation of the balancing energy reservation. Therefore, the scenarios for 2013 differ in the anticipation of balancing reserve activations. In contrast to assessing model improvements with historical data of 2013, we use the future year of 2025 to analyze the effect of a changing power plant portfolio and the possible participation of RES in the provisioning of balancing reserves. Therefore, in the 2025 scenarios we vary the participation of renewable energy sources in the balancing market.

As this modeling exercise uses a cost-minimization approach, the model results report a lower bound on the costs that can be anticipated in the balancing reserve market, not taking into account inefficiencies originating from the market design or strategic behavior.

In total we analyze seven scenarios:

- 2013: power plant and renewable portfolio of 2013;

- 2013 Anticipation: power plant and renewable portfolio of 2013 with anticipation of possible activation costs;

- 2025: power plant and renewable portfolio of 2025;

- 2025 Wind5: power plant and renewable portfolio of 2025 and wind turbines participating with $5 \%$ of their capacity in providing negative reserves;

- 2025 Wind10: power plant and renewable portfolio of 2025 and wind turbines participating with $10 \%$ of their capacity in providing negative reserves;

- 2025 Wind5+: in addition to the 2025 Wind5 scenario, wind turbines can offer $5 \%$ of their capacity to provide positive and negative reserves;

- 2025 Wind10+: in addition to the 2025 Wind10 scenario, wind turbines can offer $10 \%$ of their capacity to provide positive and negative reserves. 


\subsection{Boundary conditions}

Where possible, we use data available to the public. Load, balancing reserve requirements, crossborder exchange flows, and balancing reserve activations are based on historical time series from 2013. Renewable feed-in time series are based on TSO data from 50Hertz (2013), Amprion (2013), TenneT (2013), and TransnetBW (2013). Load time series are taken from ENTSO-E (2013-2016).

The power plant data for Germany is based on the DIW Data Documentation 72 by Egerer et al. (2014). Data from the Federal Network Agency (BNetzA, Bundesnetzagentur) has been used to augment the data further (BNetzA, 2014b; Umweltbundesamt, 2015). Cost assumptions for fuels and the $\mathrm{CO}_{2}$ price are based on Egerer et al. (2014). Power plant characteristics are derived from the DIW Data Documentation 68 by Schröder et al. (2013). Only power plants belonging to a portfolio that is pre-qualified are allowed to provide balancing reserves. ${ }^{4}$

In the application for 2025, most of the model's boundary conditions change. Prices for fuels and $\mathrm{CO}_{2}$, the power demand, the power plant portfolio, and the renewable capacities are taken from scenario B of BNetzA (2014a). The 2013 application uses given historical data with exogenous exchange flows for the surrounding countries. In the 2025 application the cross-border flows are also exogenously given. These time series have been derived from a calculation using the model dynELMOD described in Gerbaulet et al. (2014) using the same 2025 input data plus additional information from the 2014 version of the Scenario Outlook and Adequacy Forecast (SOAF) by ENTSO-E (2014) for all other European Countries.

The time-series of wind power feed-in has not only been scaled to adjust to the capacity anticipated in 2025, but has also been transformed to meet 2,000 full load hours (FLH), as technological advancements especially in the field of low-wind turbines are assumed in accordance with BNetzA (2014a, p. 111).

Data for reserved balancing power and activated balancing energy is taken from the official platform of the four German TSOs Regelleistung.net (2013). For positive secondary and tertiary reserves, $2.2 \mathrm{GW}$ and $2.5 \mathrm{GW}$ were contracted on average, respectively. For negative secondary and tertiary reserves these values differ, here $2.2 \mathrm{GW}$ and $2.7 \mathrm{GW}$ were contracted on average. As discussed in the introduction of this paper, the influence of renewables on balancing demand is highly debated and uncertain.

\subsection{Potentials and challenges for wind turbines providing balancing reserves}

When considering the provision of balancing reserves from wind turbines, technical, regulatory and market-based challenges must be taken into account. The technical challenges of sufficiently fast response times and forecast accuracy have been addressed by most market participants: In 2015, the four German TSOs published a guideline for a two-year long pilot-test to pre-qualify wind turbines for minute reserve with the aim to determine how much of a wind turbine's capacity

\footnotetext{
${ }^{4}$ The list of pre-qualified firms is derived from from https://www.regelleistung.net/. In technical terms, portfolios cannot be qualified but only single power plants. As this information is not provided on a power plant sharp basis, we abstract from this and use the portfolio sharp pre-qualification data.
} 
can be pre-qualified for balancing services (50Hertz et al., 2015). Pre-qualification of wind turbines to provide balancing reserves is the prerequisite of the participation. Technical and regulatory implementation hurdles have been taken (EWEA, 2014; Gesino, 2010; de Vos and Driesen, 2015), and in Germany two wind farms (86 MW) have been pre-qualified to provide up to $70 \%$ of their installed capacity for negative TC (50Hertz, 2016). Götz and Baumgart (2014) assume that, for a security level of $99.994 \%$, up to $30 \%$ of the entire German wind power can be used for balancing services when all turbines are pooled. Similar assumptions by Fraunhofer IWES (2014) assume a share of $10 \%$ of wind capacity would be available for balancing services in a day-ahead regime. Depending on the scenario we assume a participation of wind power for positive and negative balancing reserves. For both SC and TC they can offer a total of $5 \%$ or $10 \%$ of their forecast feed-in in the 2025 application. We do not include the possibility of PV to provide (positive or negative) balancing reserves, as we assume that until 2025 a large share of PV installations are still decentral and not remotely controllable. Moreover, new battery storages could provide balancing reserves, still we do not assume new battery storages in our analysis for three reasons: First, prices in the SC and TC market are much lower than in the PC market, hence the provision of solely PC is the most likely option, where currently pilot projects exist. Second, the therefore required arbitrage profits from the spot market are not expected in the next ten years. Third, in line with reason two and forecasts for 2025 (compare 50Hertz et al., 2016), not enough investments into battery storages are expected before 2040 in current long-term electricity investment models to play a substantial role for SC and TC balancing products.

\subsection{Future balancing reserve demand}

In the literature, the future balancing demand increase due to RES is thoroughly discussed. Most studies assume that due to the fluctuating nature of wind and solar power, the demand for balancing capacity reservation increases in order to compensate for forecast errors. Hirth and Ziegenhagen (2015) give an overview over the estimates in the literature: Here a reserve increase by $2 \%$ to $9 \%$ of additional wind power is expected in Brouwer et al. (2014), dena (2010), DLR (2012), Holttinen et al. (2011), and Lew et al. (2013). Ziegenhagen (2013) estimates an increase of $6 \%$ of additional wind capacity; with additional solar installation this value decreases to about $4 \%$. Contrary to the literature results, the absolute value of reserved balancing capacity has decreased in the years 2010-2015, although renewable capacity has increased significantly in Germany.

This contradiction can be explained by a restructuring of the German intraday and balancing market which have lead to efficiency gains. Morbee et al. (2013) and Ortega-Vazquez and Kirschen (2009) present a further explanation and show show that until a high share of RES is reached, no significant effect on the demand for balancing reserves need to be expected.

While it can be assumed that the power plant portfolio of 2025 is significantly different from the 2013 portfolio, the uncertainty regarding the future balancing reserve demand can be allocated to different developments: On the one hand, improvements in quality and precision of renewable 


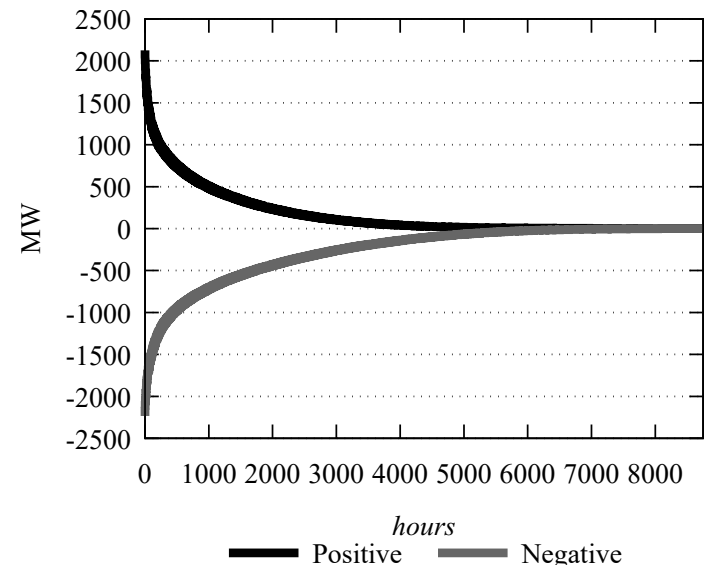

(a) Secondary Capacity

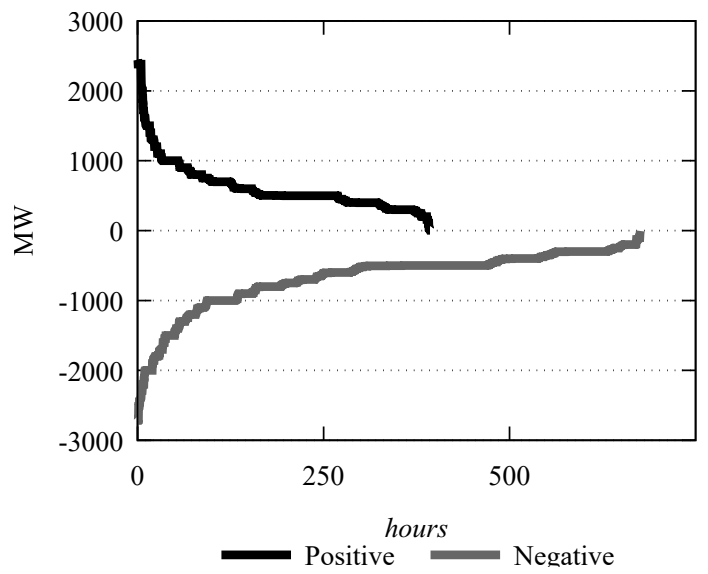

(b) Tertiary Capacity

Figure 3: Balancing reserve activation duration curves of 2013. Source: own depiction.

in-feed forecast could decrease balancing demand. On the other hand the reserve sizing mechanism influences the amount reserved substantially. With a static reserves sizing horizon, the amount of reserves is determined on a regular (e.g. quarterly) basis, whereas a dynamic reserves sizing horizon takes short term influences on the system such as renewable availability into account, possibly leading to a decreased reserves size. Breuer et al. (2013), Bucksteeg et al. (2016), and dena (2014) compare static and dynamic reserves sizing methods for future German balancing reserves and anticipate higher shares of renewable in-feed. The authors show that in case of dynamic reserves sizing the amount of required reserves only increases slightly compared to today's values. If static sizing was continued until 2030, where the amount of renewables is substantially higher than today, stronger increases up to a doubling of required reserves is estimated. Van den Bergh et al. (2016) develop a reserves sizing method in the context of cooperation between market zones, but conclude that the cost minimal approach is uncoordinated sizing, with joined activation across zones. Since most studies assume that until high shares of RES are reached, no significant influence on the balancing demand will be seen if dynamic reserves sizing is in place, and not to distort the results, we assume the same level of reserve demand for 2025 as for 2013.

The reserved balancing capacity is interlinked to the activated balancing capacity. Hence, the changing power plant portfolio does not only change the demand for reserved balancing capacity but could also change the probabilities of the activation of those capacities. On one hand, the magnitude of activation could increase due overlapping forecast errors for large RES capacities or decrease due to smaller power plant sizes. On the other hand, the relative volume of activation ( FLH of balancing capacity) could increase due to an inevitable remaining forecast error of large RES capacities or could decrease due to new possibilities to trade closer to real time and even out previous forecast errors on intraday markets. Therefore the future magnitude and relative volume of activated reserve capacities is highly uncertain. In order not to distort the results, we assume no change for the probabilities of activation. 
Figure 3 shows the duration curves of balancing reserve activations from 2013. Values above zero represent positive activations, whereas negative values represent negative balancing reserve activations. The figures show that the secondary balancing energy demand can reach above $2 \mathrm{GW}$ and below $-2 \mathrm{GW}$ in Germany.

While activations for secondary balancing energy occur throughout the year, tertiary capacity is used less frequently. At the same time, the peak activations for tertiary balancing energy are higher. Comparing these numbers to the peak load of about $83 \mathrm{GW}$ and an overall energy demand of about $535 \mathrm{TWh}$ in Germany shows that the energy activated on the balancing reserve markets is - by its nature - relatively small.

Data published by the TSOs shows the average values for balancing reserve activation within 15 minutes. These quarter hourly values are used to generate blocks with specific activation frequencies for each country, product, and direction. In this application we use ten different blocks for each balancing product. These activation frequencies are used to estimate the activation cost when reserving balancing power. See Section 2 for an explanation of activation frequencies and blocks. The quarter hourly values are also used to model the activation of balancing reserve during the call. This could result in an underestimation of possibly high ramping gradients as these activation could occur within seconds in practice.

\section{Results and discussion}

The application of ELMOD-MIP yields interesting insights into a possible development of the German balancing reserve market of 2025 and confirms an overall good representation of the German electricity market of 2013, as the realized electricity generation levels of 2013 are met by the model values (Figure 4$).^{5}$

In 2013, lignite and hard coal produced nearly half of the German electricity demand, followed by nuclear power and natural gas. RES accounted for around a quarter of the electricity demand. The generation levels of 2025 show strongly increased production by renewable energy sources compared to 2013, corresponding to the increase in installed capacity and improved FLH. Consequentially, also following the anticipated decrease in installed capacity of lignite and coal power plants, the production of lignite and coal-fired power plants is reduced significantly. No more nuclear electricity generation capacities are present in 2025. The gas-fired electricity generation level increases, as not only gas-fired power plants are used, but also "decentral CHP" generation is partly based on gas.

The model's spot price calculations also match the observed spot price values. The 2013 spot market price duration curve (Figure 5) as well as the average market price are nearly met by the model results with $36.5 € / \mathrm{MWh}$ model average price compared to $37.8 € / \mathrm{MWh}$ realized electricity price.

\footnotetext{
${ }^{5}$ Small deviations of the realized values to the model results are present, which are caused by different technology assignments for some power plants, especially regarding the categorization between "Coal" and "Miscellaneous." Furthermore, the production of gas-fired power plants is slightly underestimated.
} 


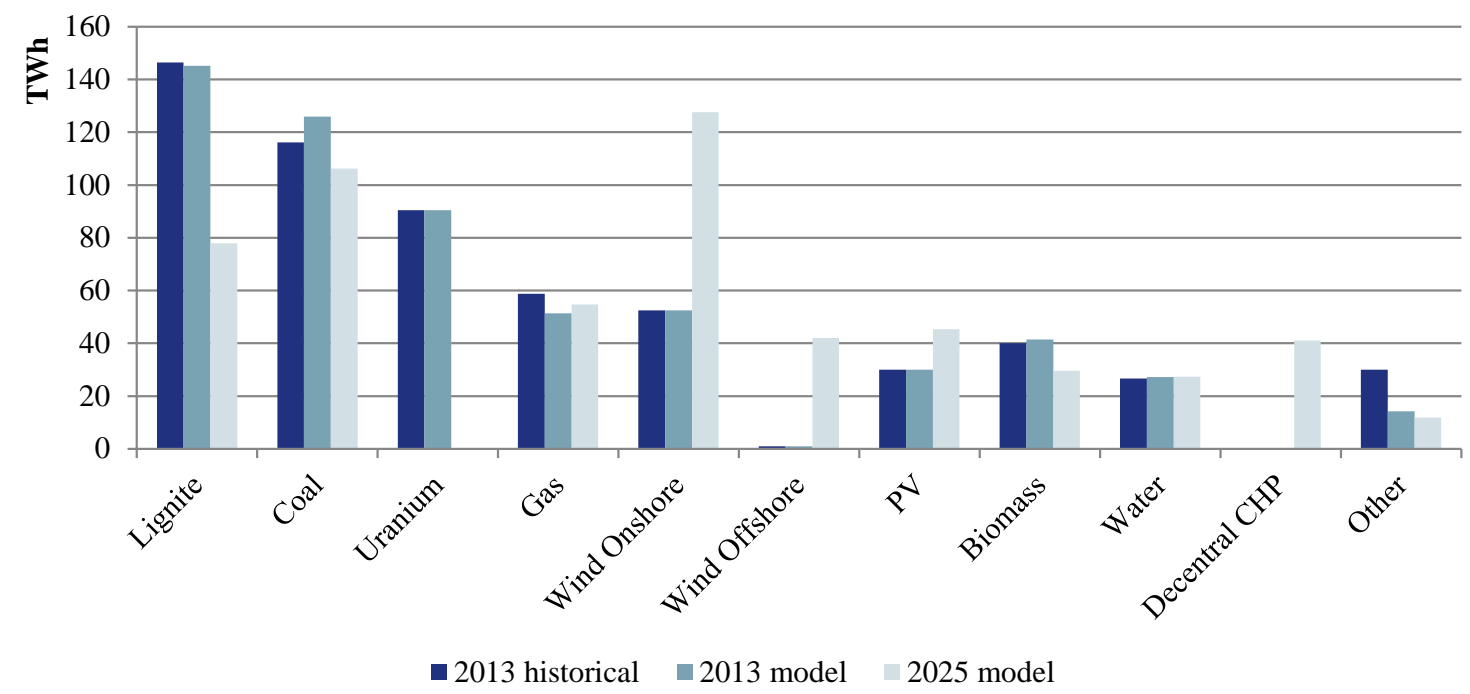

Figure 4: Spot market generation by fuel for 2013 and 2025. This figure does not differentiate between the balancing reserve scenarios, as the effect on the spot market is minimal. Source: own depiction.

In 2025, the new power plant portfolio and increased generation from renewables lead to a different price duration curve with a slightly higher average price of $38 € / \mathrm{MWh}$, which corresponds to current forecasts for 2025 (cf. Oei et al., 2015). Furthermore, we observe over 1,300 hours where the spot price is close to $0 € / \mathrm{MWh}$, which is on the one hand caused by the uptake in renewable feed-in and on the other hand result of the model formulation, as the interaction with the neighboring countries is determined in a preparatory model run using the model dynELMOD described in Gerbaulet and Lorenz (2017).

\subsection{Balancing reserve provision}

Positive reserves are mainly provided by coal (40\%) and gas (40\%) in 2013. Lignite and pumped hydro storage capacities provide the remaining part of the reserves (Figure 6). Nuclear capacities do not participate in providing positive reserves. Similar technology shares for reservation of SC and TC are observable. For TC, more fast starting gas turbines are reserved that can be offline during the spot market dispatch. The inclusion of activation anticipation has a small but noticeable effect on the reservation by the different fuel types. Reservation of gas and oil fueled power plants is slightly reduced and replaced by water and coal fueled power plants, as their marginal costs, and therefore possible activation costs, are lower.

For the 2025 scenario, the reservation shifts towards lignite and pumped storage plant (PSP) reservation and fewer gas capacities. In comparison to 2013, lignite power plants are more often below full capacity in the spot market due to an increased variation of the residual load. Therefore they are able to provide more positive capacity without opportunity costs. In contrast, CHP 


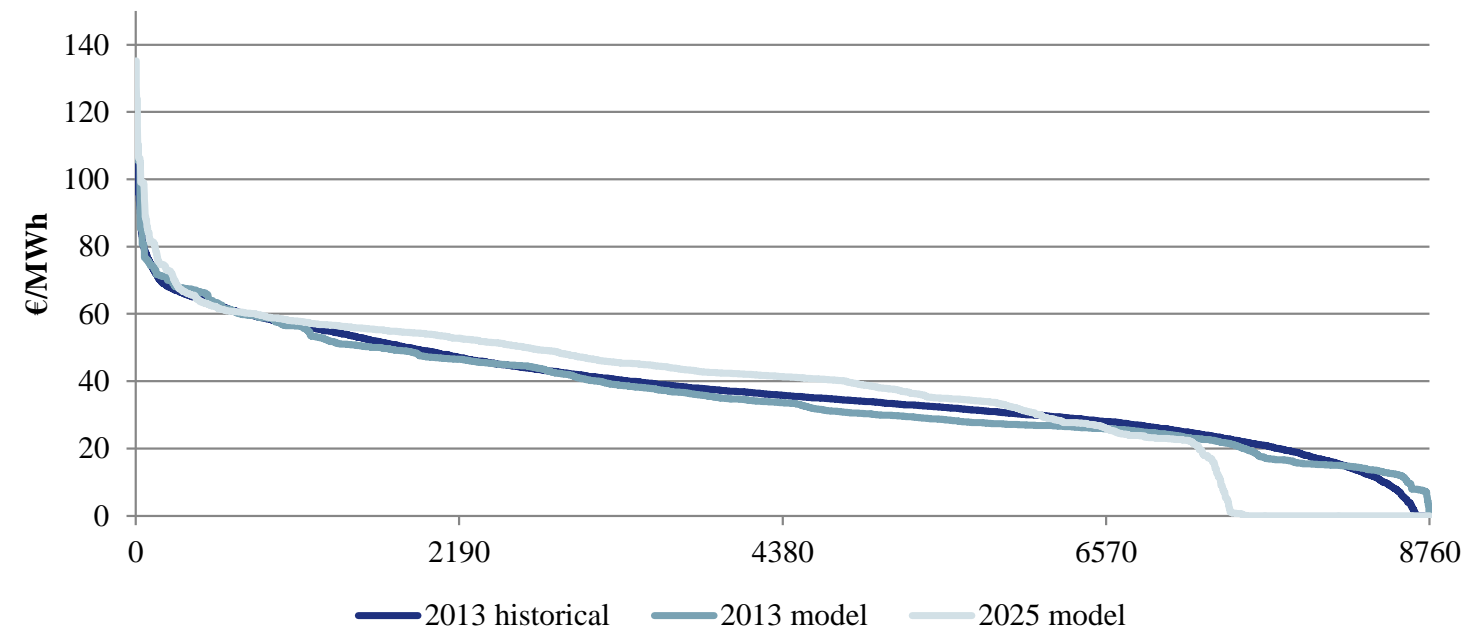

Figure 5: Spot Price duration curves for 2013 and 2025. This figure does not differentiate between the balancing reserve scenarios as the effect on the spot market is minimal. Source: own depiction.

power plants show higher FLH due to two factors: first, fewer CHP plants are in the market to provide heat. Second, more CHP plants are equipped with heat storage that allows for complete shutdowns when demand is low. These two factors lead to higher utilization, which in return leads to less options for reserve provision with low opportunity cost.

For TC the usage of gas-fired power plants increases in 2025 with the results of an almost exclusive provision of positive TC reservation by gas. This is caused by the high flexibility of gas-fired power plants compared to coal, allowing them to be offline and use their fast-starting gas turbines to start when needed. The possibility to use fast starting power plants is not given for SC, which explains the interesting contrary developments in SC and TC. However, in times with high spot market prices, gas fired power plants are used in both markets as their marginal cost are now close to the market price, which allows for cheap reserve provision. The PSP capacities are mostly used for SC reservation. The effect of the scenarios 2025 Wind5 and 2025 Wind10 on positive reservation is small as they only include participation of wind in the negative balancing market. Clearly a much larger effect can be observed in 2025 Wind5 + and 2025 Wind10+. It is slightly different for SC and TC. For SC, wind replaces a significant share of gas reserves. The volumes are similar for the $5 \%$ and $10 \%$ wind participation. For TC, wind replaces less capacities as most of them are already provided by cheap offline gas turbines. The difference between $5 \%$ and $10 \%$ is bigger than for SC, indicating that first, costly SC is provided by wind and only when excess wind capacity is available the already cheap TC is replaced.

The reservation of negative balancing capacity (Figure 7) in the 2013 scenario is distributed between coal (30\%), lignite (29\%), run-of-river (18\%), natural gas (10\%) and PSP (7\%). Taking into account possible activation probabilities in the scenario 2013 Anticipation alters the 


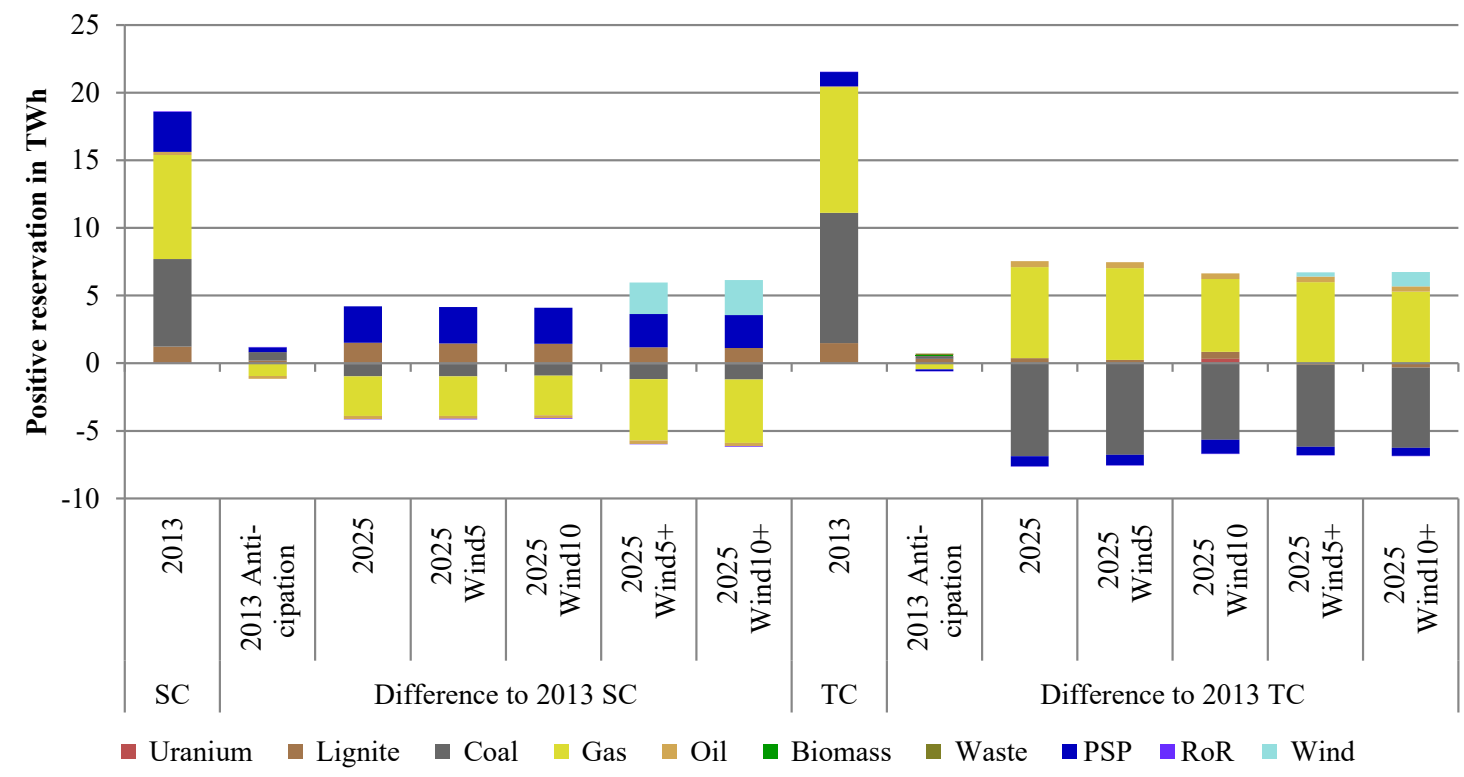

Figure 6: Positive balancing capacity reservation by product, scenario and fuel for 2013 and 2025

reservation towards more fossil based capacities, as potential fuel savings in the case of activation are anticipated, which would not occur with run-of-river capacities.

In the 2025 case without wind, the reserved capacity also shifts to coal, gas, and PSP, reducing lignite and run-of-river reservation. The reduced FLH of lignite lead to less possibilities to provide negative reserves without additional costs. In contrast, one can see an increased provision by gas fired power plants, as these power plants are now producing due to a spot price above their marginal costs and hence above their minimum load. Therefore, they have the potential to ramp down and provide negative reserves.

With increased wind participation for negative reserves in the scenarios 2025 Wind5 and 2025 Wind10 wind is used increasingly and provides $53 \%$ of the SC capacity and about $33 \%$ of the TC capacity in the scenario 2025 Wind10. The participation of wind turbines in providing negative reserves reduces mainly the provision of coal but for high shares also of PSP and gas. As expected, the provision of positive reserves by wind in the 2025 Wind5+ and 2025 Wind10+ scenarios does not have an significant influence on the provision of negative reserves.

\subsection{The system cost of balancing reserves}

Comparing the computed costs for reservation with the observed costs and between the scenarios provides insights whether the model is able to replicate the current market setting sufficiently well, and what the effect of the novel model formulation with activation anticipation is. Also, the cost estimate for 2025 can be analyzed. 


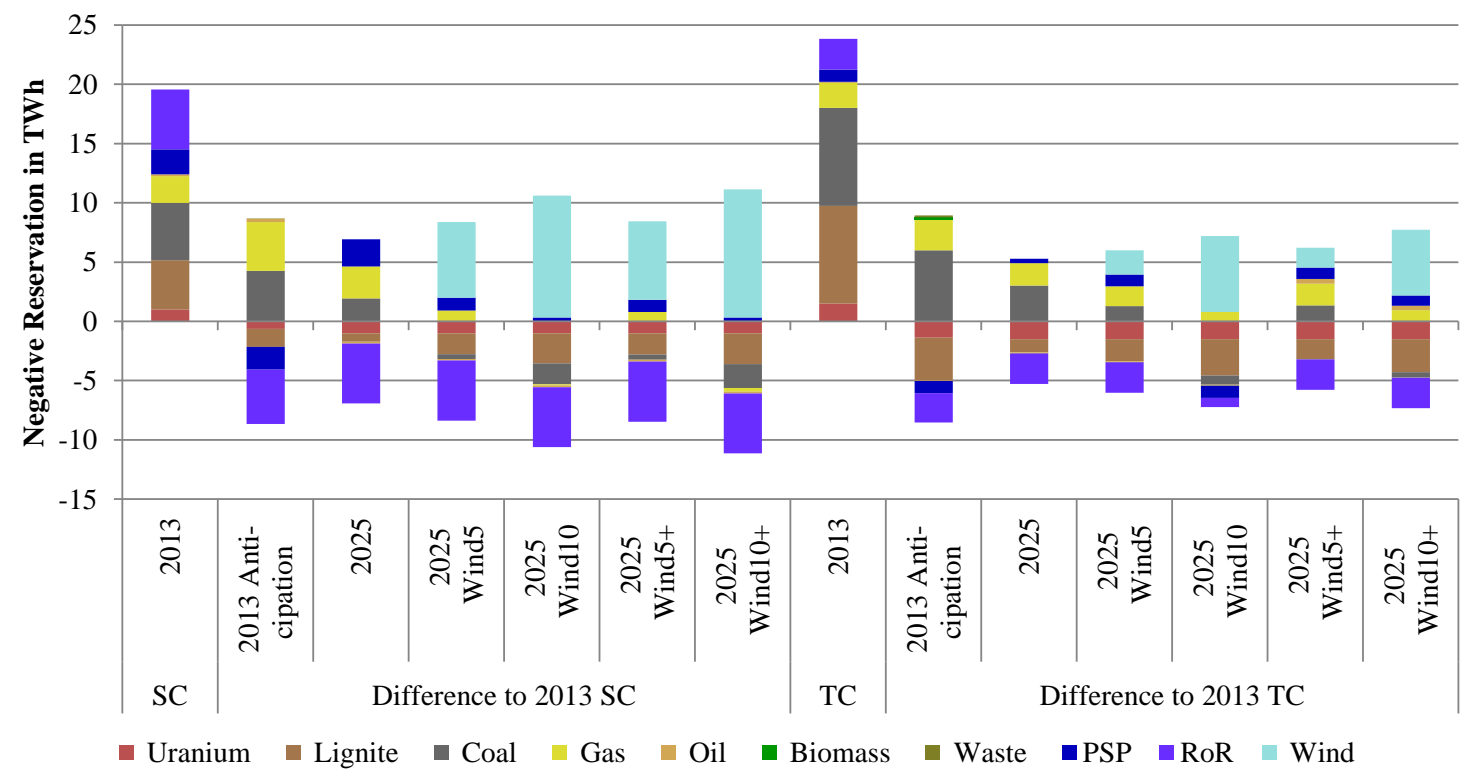

Figure 7: Negative balancing capacity reservation by product, scenario and fuel for 2013 and 2025

Independent of the scenario, the calculated cost for reserving SC and TC balancing capacities in 2013 are lower than the 423 million $€$ costs observed (Figure 8). This is mainly a result of the assumption of hourly reserve capacity reservation as well as underestimated costs for negative balancing capacity. In the current market setting, prices for negative reserves are not mainly driven by market fundamentals but also by market participant behavior and price expectations. Especially in a setting with many plants running at or near full capacity, the cost of providing negative balancing capacity should be close to zero. Thus, replicating the historical results in a fundamental electricity model is challenging.

While the cost for positive balancing capacity reservation in the scenario 2013 do not fully meet the values observed, the comparison with included anticipation in the scenario 2013 Anticipation shows a slightly better approximation of the positive balancing reservation cost with 273 million $€$. Here, generation capacities with higher opportunity cost on the spot market but potentially lower anticipation cost are reserved. The overall calculated cost are still lower than observed, especially as the price for negative reserves is underestimated by the model.

The cost estimate for negative reservation is not improved by the inclusion of anticipation. Here overall negative costs are observed, because hourly prices are often negative. This is caused by the anticipation of potentially saved fuel costs in the model, leading to a negative price in this fundamental model setting. Thus, while the overall reservation structure and prices for positive reserves are improved in the scenario 2013 Anticipation, the representation of prices for negative balancing cannot be improved.

In 2025 we see an overall reservation cost increase throughout the scenarios. The reservation cost range between 761 million $€$ in the 2025 scenario to 450 million $€$ in the scenario 2025 


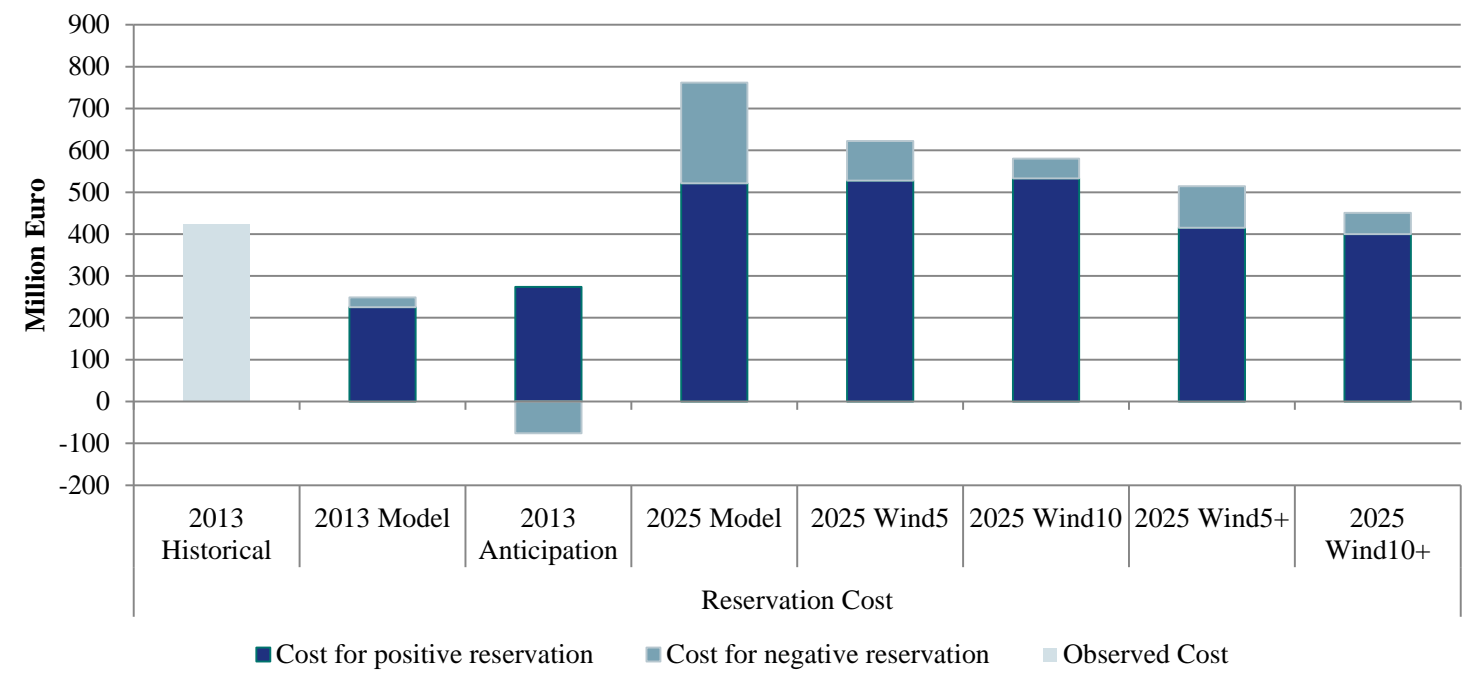

Figure 8: Total cost for reserves provision by scenario for 2013 and 2025. Source: BNetzA (2015) and own calculations.

Wind10+. The overall cost increase can be explained by a lower supply for balancing capacity as a consequence of the changes in the German power plant portfolio. During times of very low residual load, power plants must now just be online to provide reserves, inducing high costs due to minimum load constraints. Additionally, the shift towards gas-fueled power plants increases the part load costs. Within the scenarios for the year 2025 the overall costs decrease with ascending wind participation as expected. Wind capacities mostly replace fossil capacities during times when residual demand is very low. During this time these capacities would not run normally (above minimum load) due to the low market price, except for providing reserves. Hence, this "unnecessary" generation cost can be avoided. The additional benefit of $10 \%$ instead of $5 \%$ percent of wind turbines participating is different for positive and negative reserves. While negative reserve cost are further reduced when increasing the number of participating turbines, the cost for positive reservation do not decrease substantially. Furthermore, the relative cost savings stemming from wind participation in negative reserves are higher than from participation in positive reserves, as for negative reserve provision, no ex-ante curtailment of wind feed-in is necessary. For positive reserve provision, wind feed-in must be curtailed to enable upward potential. Thus, the opportunity cost for providing positive reserves are much higher than for negative reserves. Therefore, only in situations with a very residual load close to or below zero (which are still rare in 2025) it is beneficial to provide positive balancing reserves with wind turbines. Hence, the resulting cost savings by wind providing positive reserves, are lower. In systems with a higher share of fluctuating RES and more hours with low residual load, the use of positive reserves by wind turbines become a sensible option.

In line with the reservation cost, the activation cost differ depending on scenario. The results show that in the 2013 Anticipation scenario activation cost for positive and negative balancing 


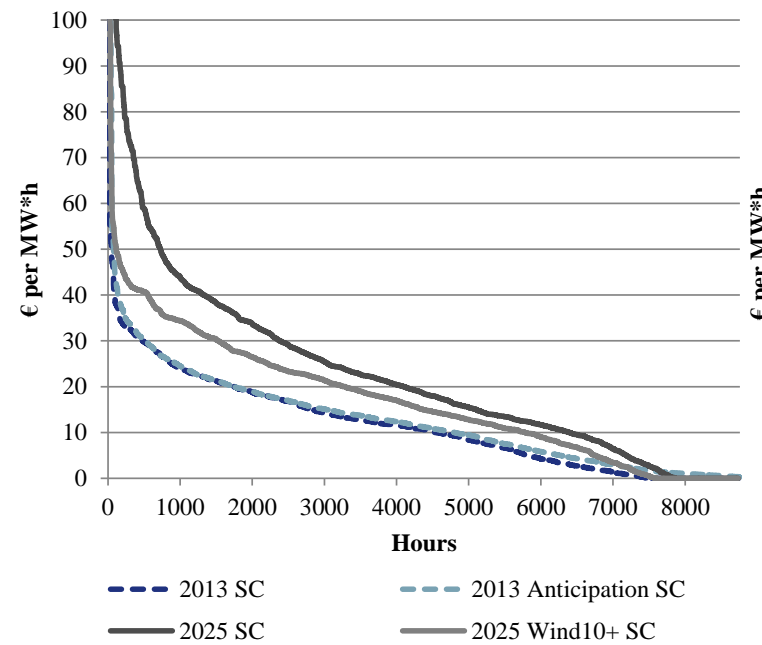

(a) Price of positive reservation $\mathrm{SC}$

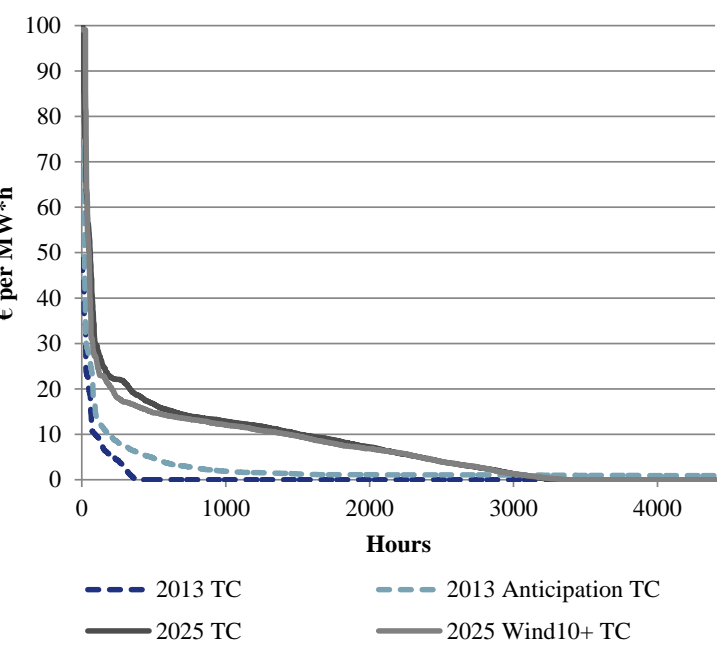

(b) Price of positive reservation TC

Figure 9: Price duration curves for positive reservation by product and scenario for 2013 and 2025. The scenario 2025 Wind5 is not depicted for clarity. The duration curve of 2025 Wind5 is directly between 2025 and 2025 Wind10. Source: own calculations.

Table 1: Average marginal prices for balancing capacity reservation by scenario

\begin{tabular}{ccccccccc}
\hline$€ / \mathrm{MW} \cdot \mathrm{h}$ & Product & 2013 & $\begin{array}{c}\text { 2013 } \\
\text { Anticipation }\end{array}$ & 2025 & $\begin{array}{c}\text { 2025 } \\
\text { Wind5 }\end{array}$ & $\begin{array}{c}\text { 2025 } \\
\text { Wind10 }\end{array}$ & $\begin{array}{c}\text { 2025 } \\
\text { Wind5+ }\end{array}$ & $\begin{array}{c}\text { 2025 } \\
\text { Wind10+ }\end{array}$ \\
\hline Positive & SC & 11.66 & 12.87 & 23.30 & 23.49 & 24.32 & 17.68 & 17.13 \\
reservation & TC & 0.40 & 1.59 & 4.14 & 4.21 & 4.72 & 4.06 & 3.82 \\
\hline Negative & SC & 1.03 & -3.61 & 7.63 & 2.39 & 1.14 & 2.55 & 1.20 \\
reservation & TC & 0.14 & -0.39 & 3.84 & 2.03 & 1.06 & 2.08 & 1.14 \\
\hline
\end{tabular}

Source: own calculation.

energy can be reduced in comparison to the 2013 scenario by up to $10 \%$. For the 2025 scenario activation cost for positive and negative balancing energy are increasing by $15 \%$. These cost for negative balancing energy are significantly reduced with the participation of wind in the 2013 Wind5 scenario and 2013 Wind10 scenario. Similarly, the cost for positive balancing activation are significantly reduced in the 2013 Wind5+ scenario and 2013 Wind10+ scenario.

\subsection{Prices on balancing reserve markets}

We now analyze the price duration curves as well as the average reservation price for the balancing products. This allows further insights into the effect of the scenario variations regarding the price distribution. Table 1 gives an overview of the observed average marginal prices for balancing capacity reservation. Looking at the market results for positive balancing capacity of 2013, we observe an average marginal price for positive $\mathrm{SC}$ reservation of $11.66 € / \mathrm{MW} \cdot \mathrm{h}$. This comes close to the historical average of $12 € / \mathrm{MW} \cdot \mathrm{h}$ (Figure 9a). The average marginal price for positive 
TC reservation is much lower with $0.4 € / \mathrm{MW} \cdot \mathrm{h}$ (Figure $9 \mathrm{~b}$ ). Also the historical market results for positive TC reservation shows a much lower price than than SC, still the model price is significantly lower than the historical results. ${ }^{6}$ In the scenario 2013 Anticipation the average price for positive SC reserves increases as expected by $1 € / \mathrm{MW} \cdot \mathrm{h}$ to $12.87 € / \mathrm{MW} \cdot \mathrm{h}$. On the right hand side the low prices increase slightly. This is a result of the call anticipation, the peak prices remain unaffected, as other influencing factors are relevant here. The price duration curve for TC in 2013 Anticipation shows higher prices overall, showing an improved representation of the historical results with $1.59 € / \mathrm{MW} \cdot \mathrm{h}$, almost matching the observed average of $1.51 € / \mathrm{MW} \cdot \mathrm{h}$ of 2013.

In 2025, the average marginal price for SC increases to $23.3 € / \mathrm{MW} \cdot \mathrm{h}$, while prices for TC increase to $4.1 € / \mathrm{MW} \cdot \mathrm{h}$. With the participation of wind in the positive reserve provision the average marginal price for SC decreases to $17.7 € / \mathrm{MW} \cdot \mathrm{h}$ for $2025 \mathrm{Wind} 5+$ and $17.1 € / \mathrm{MW} \cdot \mathrm{h}$ for 2025 Wind10+. Therefore, only the load duration curve for the 2025 Wind10+ is shown. Especially the high prices for SC can be reduced with wind participation. Prices for TC decrease less heavily to $4 € / \mathrm{MW} \cdot \mathrm{h}$ for $2025 \mathrm{Wind} 5+$ and $3.8 € / \mathrm{MW} \cdot \mathrm{h}$ for $2025 \mathrm{Wind10+}$. As expected, the provision of negative reserves by wind turbines in the 2025 Wind5 and 2025 Wind10 scenarios does not have a significant impact on prices for positive reserves.

In 2025 the general price level is higher, and higher price peaks are observed. This price increase stems from different factors: First, the German power plant portfolio is characterized by higher average marginal cost than in 2013, which mainly applies to gas-fired power plants. Furthermore, the gas-fired power plants' relative part-load efficiency decrease is higher than for other plant types, leading to higher part load cost. ${ }^{7}$ Second, more situations with very low residual load occur, in which no or very few dispatchable thermal power plants are online or have spare generation capacity. Thus, additional plants need to be started up and operating in minimum load just to provide available capacity for possible reserve energy activation.

Third, the increased flexibility of CHP plants in 2025 (e.g., due to additional heat storage) results in reduced online times and higher load factors during electricity production. Hence, CHP plants produce less often when their marginal costs are above the market price. Thus, the amount of must-run capacity is reduced in 2025, which would allow for an reserve provision without opportunity cost. ${ }^{8}$

Analyzing the negative prices (Figure 10) for reserve capacity shows a different picture: In 2013 we observe an average marginal price for negative SC of $1.03 € / \mathrm{MW} \cdot \mathrm{h}$, which is significantly lower than the actually observed market outcome of $40 € / \mathrm{MW} \cdot \mathrm{h} .{ }^{9}$ Hence, we find that prices for

\footnotetext{
${ }^{6}$ In the current German balancing market pay-as-bid is used in contrast to the marginal prices reported in our model. According to Kahn et al. (2001) all pay-as-bid bids in such a market setting will converge towards the market clearing price in the long term, not taking into account risk-aversive behavior. Therefore, the marginal pay-as-bid price and our marginal price can be compared.

${ }^{7}$ See Section 2 for an explanation on cost components driving the price of reserve capacity.

${ }^{8}$ See footnote 7 .

${ }^{9}$ In the actual market outcome for 2013 , the average marginal price for negative reserves of $40 € / \mathrm{MW} \cdot \mathrm{h}$ is much higher than the average bid price of $8 € / M W \cdot h$. In the market for positive reserves the average marginal price and average price are much closer.
} 

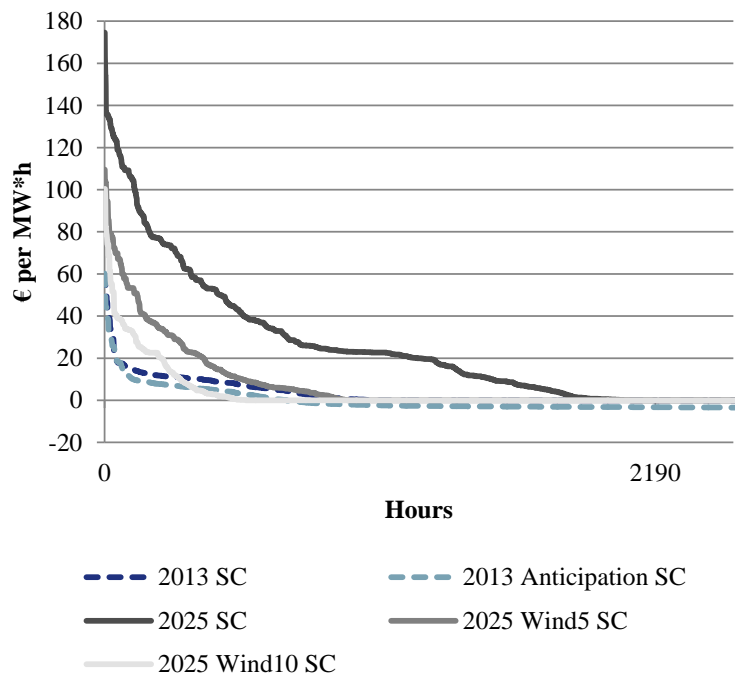

(a) Price of negative reservation SC

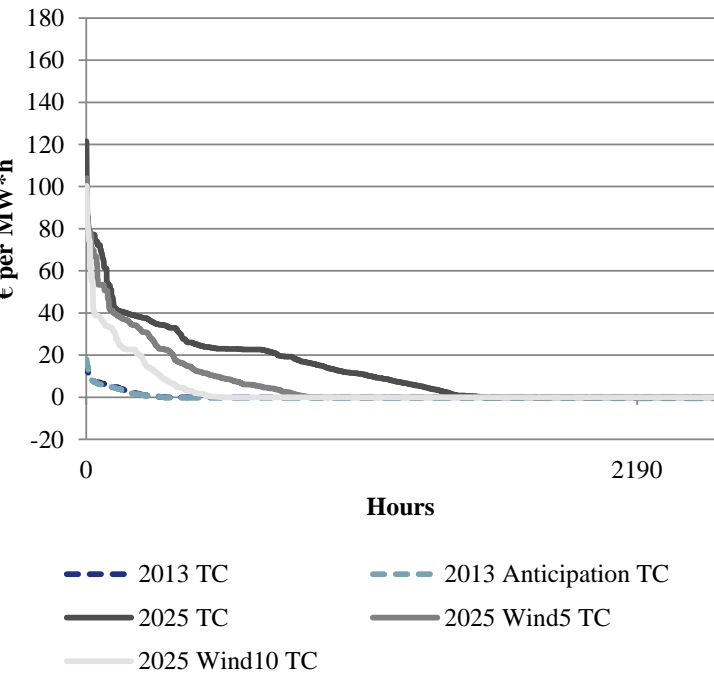

(b) Price of negative reservation TC

Figure 10: Price duration curves for negative reservation by product and scenario for 2013 and 2025. Source: own calculations.

negative reserves are not fully replicable using a fundamental model, which is inline with current literature. ${ }^{10}$

Looking at the results for negative reserves in the 2013 Anticipation scenario we observe negative prices for a large percentage of hours. This is a result of the model formulation, as the potential fuel savings are included in the reservation price. In this case, the novel model formulation does not lead to more realistic price results.

In 2025 the average prices for negative $\mathrm{SC}$ increase to $7.63 € / \mathrm{MW} \cdot \mathrm{h}$; peak prices increase from $60 € / \mathrm{MW} \cdot \mathrm{h}(2013)$ to $174 € / \mathrm{MW} \cdot \mathrm{h}$. Prices are still low in general, as prices above zero are observed in less than 2,000 hours. The inclusion of wind participation in the 2013 Wind5 and 2013 Wind10 scenarios influences the prices visibly, as the price averages are much lower with an average price of $2.39 € / \mathrm{MW} \cdot \mathrm{h}$ and $1.14 € / \mathrm{MW} \cdot \mathrm{h}$, respectively. In contrast to positive reserves, additional wind turbines in the 2013 Wind10 scenario can further reduce the prices compared to 2013 Wind5 scenario.

For negative TC, average marginal prices close to zero are observable in 2013 that increase to $3.84 € / \mathrm{MW} \cdot \mathrm{h}$ in the 2025 scenario. The 2025 Wind5 and 2025 Wind10 scenarios reduce the price for negative TC reservation again, to $2.03 € / \mathrm{MW} \cdot \mathrm{h}$ and $1.06 € / \mathrm{MW} \cdot \mathrm{h}$, respectively. In line with the results for $\mathrm{SC}$, additional wind turbines further reduce the prices. As expected, the provision of positive reserves by wind turbines in the 2025 Wind5 + and 2025 Wind10+ scenarios does not have a significant impact on prices for positive reserves.

\footnotetext{
${ }^{10}$ This is confirmed by Bucksteeg et al. (2014) who compute prices for negative reserves close to zero in a fundamental model approach and thus only analyze the prices for positive balancing capacity.
} 
The price increase for negative reserves in the 2025 scenarios stems from the fact that conventional generation is running at minimum load (or is even offline) in more hours. Thus, some plants must produce electricity only to provide negative reserves, even if their marginal cost are above the spot price. The provision of negative balancing reserves by wind reduces these cost significantly, as in situations with low residual demand wind feed-in is often very high. This allows for large quantities of negative balancing reserves being provided by wind turbines, which in return allows for reducing the amount of conventional power plants that have to be online merely to provide negative reserves.

\subsection{Discussion of limitations}

This paper's findings need to be discussed in the context of the model's limitations as well as assumptions regarding the regulatory and technical boundary conditions.

We abstract from any strategic behavior that the market participants might apply, which might lead to higher prices on the spot and balancing markets and could increase costs. Furthermore, we abstracts from some characteristics of the actual balancing market design, that includes product durations of more than an hour as well as portfolio bids, where an actor controlling multiple power plants can bid into the balancing market without revealing in advance which power plant will provide the balancing reserves. However, for power plants within large portfolios this approximation leads to no changes, only for power plants in small portfolios these approximation could lead to an overestimation on their flexibility. Together with the neglection of uncertainty of RES infeed and load realization, a perfect adjustment of the reserved capacities neglecting any market inefficiencies is possible. Thus, the true cost of the balancing reserve system is likely underestimated. The increasing market volume would also increase the absolute cost savings. Hence, the absolute cost savings observed in the model are a lower bound, as the relative cost savings are not changing, because the different scenarios are based on the same assumptions.

Apart from strategic behavior, most technical constraints can only be approximated in a large-scale unit-commitment model. This includes also limitations on wind turbine output when withholding capacity to provide balancing reserves. As the future output of a wind turbine always includes some level of uncertainty, it can be complicated to determine the capacity that must be withheld to provide balancing reserves with a sufficient high level of security. Thus, real opportunity cost of wind turbines providing balancing reserves, could be slightly higher, although the general picture will not change.

\section{Conclusions}

This paper presents the fundamental market model ELMOD-MIP which includes a detailed approach to model balancing provision for 2013, and analyzes a future scenario for the German balancing market of 2025. ELMOD-MIP includes the probability of reserve activation during the calculation of reserve capacity allocation. This allows us to closer approximate the behavior 
of market participants. In the future scenario of 2025, the influence of a changed power plant portfolio on prices and allocation of reserves is analyzed. Furthermore, the influence of wind power as a new market participant for the provision of positive and negative reserves is analyzed. The model shows a good representation of the spot and balancing markets. The novel approach leads to an improved representation of the historical market results for positive reserves, especially for TC. For negative reserves the representation cannot be improved substantially. Here, besides market fundamentals, strategic behavior and price expectations are important price drivers, which are hard to replicate in a fundamental electricity model.

The application of ELMOD-MIP to scenarios of the year 2025 shows an increase of prices for positive and negative reserves, when no entrance of new market participants is anticipated. With the participation of wind turbines the cost for balancing provision is reduced by $40 \%$, but remains above 2013 values. The relative cost savings stemming from wind participation are higher for negative reserves, as no previous curtailment of feed-in is required for reservation in contrast to positive reserve provision by wind turbines. The participation of wind turbines especially reduces the occurrence of peak prices for positive and negative reserves in 2025. This reduction effect occurs even with a relatively low share where wind turbines participate with only five percent of their capacity.

Further fostering the process of allowing wind turbines to participate in the German reserve market favorable. Although participation of wind turbines in balancing reserves is already reality, the current motions to adapt the current market setup to improve timing and flexibility of the auction process by decreasing lead times between bid and delivery, shorter product lengths, or an adapted bidding procedure to include marginal cost pricing could improve the market environment to enable the findings discussed in this paper.

\section{Acknowledgments}

The authors would like to thank Andreas Bloeß, Christian von Hirschhausen, Friedrich Kunz, Alexander Weber, and Jens Weibezahn for valuable comments and support. Casimir Lorenz gratefully thanks the Reiner Lemoine-Stiftung for financing his research work.

\section{A. Nomenclature}

The following tables give an overview of all sets, parameters, and variables used in ELMOD-MIP. 
Table 2: Sets in ELMOD-MIP

\begin{tabular}{ll}
\hline Sets & \\
\hline$t, t t$ & Time \\
$r$ & Region \\
$p$ & Power plants \\
$c$ & Subset of conventional power plants \\
$u$ & Subset of fast starting power plants \\
$o$ & Subset of must-run power plants \\
$s$ & Subset of PSP powerplants \\
$b l$ & Blocks of balancing power \\
$b$ & Balancing power product \\
\hline
\end{tabular}

Table 3: Parameters in ELMOD-MIP

\begin{tabular}{|c|c|}
\hline \multicolumn{2}{|c|}{ Parameters } \\
\hline$c_{p}^{\text {start }}$ & Cost per start-up \\
\hline$c_{p}^{\text {down }}$ & Cost per shut-down \\
\hline$m c_{c}$ & Marginal generation costs \\
\hline$g_{p}^{\max }$ & Maximum generation \\
\hline$g_{p}^{\min }$ & Minimum generation if online \\
\hline$g_{t}^{\text {sol }}$ & Solar energy feed-in \\
\hline$g_{t}^{\text {wind }}$ & Wind energy feed-in \\
\hline$g_{t}^{b i o}$ & Biomass energy feed-in \\
\hline$r_{p}^{\text {down }}$ & Maximum ramping down speed [\% per hour] \\
\hline$r_{p}^{u p}$ & Maximum ramping up speed [\% per hour] \\
\hline$q_{t}^{\text {spot }}$ & Electricity load \\
\hline$q_{b, b l, r, t}^{r e s v e g}$ & Total amount of negative balancing power needed \\
\hline$q_{b, b l, r, t}^{r e s v}$ & Total amount of positive balancing power \\
\hline$q_{b, r, t}^{\text {call, neg }}$ & Total Negative activation in per region, time, and product \\
\hline$q_{b, r, t}^{\text {call, pos }}$ & Total Positive activation in per region, time, and product \\
\hline$f_{r, r r}^{\max }$ & Max flow \\
\hline$f r q_{b l, b}$ & Activation frequency of balancing reserve in a specific block \\
\hline$l_{s}^{\max }$ & Maximum storage level \\
\hline$l_{s}^{\min }$ & Minimum storage level \\
\hline$v_{s}^{\max }$ & Maximum storage release \\
\hline$w_{s}^{\max }$ & Maximum storage loading \\
\hline$\eta_{s}$ & Storage efficiency \\
\hline$g_{s, t}^{\text {nat }}$ & Natural inflow into storage \\
\hline
\end{tabular}

Table 4: Binary Variables in ELMOD-MIP

\begin{tabular}{ll}
\hline Binary & \\
Variables & \\
\hline$O N_{c, t}$ & Plant status \\
$U P_{c, t}$ & Plant startup variable \\
$D N_{c, t}$ & Plant shutdown variable \\
$S B_{b, b l, u, t}$ & Activation from standby per product and block for fast starting plants \\
\hline
\end{tabular}


Table 5: Variables in ELMOD-MIP

\begin{tabular}{|c|c|}
\hline Variables & \\
\hline Cost & Objective value: total cost \\
\hline Cost ${ }^{\text {gen }}$ & Generation cost \\
\hline Cost Cesv $^{\text {res }}$ & Total balancing reservation cost \\
\hline Cost $^{\text {call }}$ & Total balancing activation cost \\
\hline Cost $^{\text {start }}$ & Total start up cost \\
\hline Cost $^{\text {down }}$ & Total shut down cost \\
\hline$G_{c, t}$ & Conventional generation in MW \\
\hline$G_{p, t, b l, b}^{r e s v, p o s}$ & Positive reserved balancing power assigned to a plant \\
\hline$G_{p, t, b l, b}^{p, i, b e g}$ & Negative reserved balancing power assigned to a plant \\
\hline$G_{s, t, b l, b}^{\text {pesu, }, \text { os }, A}$ & Positive reserved balancing power of a PSP (active $=$ more generation $)$ \\
\hline$G_{s, t, b l, b}^{\text {resu,pos }, P}$ & Positive reserved balancing power of a PSP (passive = less pumping) \\
\hline$G_{s, t, b l, b}^{\text {resu, neg, } A}$ & Negative reserved balancing power of a PSP (active $=$ more pumping) \\
\hline$G_{s, t, b l, b}^{\text {resu, neg }, P}$ & Negative reserved balancing power of a PSP (passive $=$ less generation) \\
\hline$G_{b, p, t}^{\text {call, pos }}$ & Positive activated balancing energy \\
\hline$G_{b, p, t}^{c a l l, \text { neg }}$ & Negative activated balancing energy \\
\hline$F_{r, r r, t}^{s p o t}$ & Spot market flow \\
\hline$F_{b, b l, r, r r, t}^{r e s v, p o s}$ & Reservation of positive balancing flow \\
\hline$F_{b, b l, r, r r, t}^{r e s v i n g}$ & Reservation of negative balancing flow \\
\hline$F_{b, r, r r, t}^{\text {call } p \text { os }}$ & Positive balancing flow \\
\hline$F_{b, r, r r, t}^{c a l l, \text { neg }}$ & Negative balancing flow \\
\hline$F_{b, b l, r, r r, t}^{r e s v, p o s, g e 0}$ & Positive part of the reservation of positive balancing flow \\
\hline$F_{b, b l, r, r r, t}^{r e s v, p o s}$ & Negative part of the reservation of positive balancing flow \\
\hline$F_{b, b l, r, r r, t}^{r e s v e n}$ & Positive part of the reservation of negative balancing flow \\
\hline$F_{b, b l, r, r r, t}^{r e s v, \text { neg }}$ & Negative part of the reservation of negative balancing flow \\
\hline Frq $\max _{u, t}$ & Highest possible Activation Frequency in specific hour \\
\hline$P S P_{s, t}^{d i s c a r d}$ & Discard of excess water \\
\hline$P S P_{s, t}^{D}$ & Storage loading (pumping) \\
\hline$P S P_{s, t}^{G}$ & Storage release (generation) \\
\hline$P S P_{s, t}^{L}$ & Storage level \\
\hline
\end{tabular}




\section{References}

50Hertz, Amprion, TennetT, and TransnetBW (2015). Leitfaden zur Präqualifikation von Windenergieanlagen zur Erbringung von Minutenreserveleistung im Rahmen einer Pilotphase. Berlin, Germany. URL: https://www.regelleistung.net/ext/download/pqWindkraft (visited on October 17, 2016).

50Hertz, Amprion, TenneT, and TransnetBW (2016). Szenariorahmen für die Netzentwicklungspläne Strom 2030 - Entwurf der Übertragungsnetzbetreiber. Berlin, Germany. URL: http : / / data.netzausbau.de/2030/Szenariorahmen_2030_Entwurf .pdf (visited on April 20, 2016).

50Hertz (2013). Netzkennzahlen. URL: http://www.50hertz.com/de/Kennzahlen (visited on March 12, 2015).

50Hertz (2016). Wind farms can participate in balancing market. Press Release. Berlin. URL: http : / / www . 50hertz . com/Portals/3/Content/NewsXSP/50hertz_flux/Dokumente/ 20160217_PM_50Hertz_Praequalifizierung_Windkraft_EN.pdf.

Abbasy, A., R. A. C. van der Veen, and R. Hakvoort (2010). Timing of Markets - the Key Variable in Design of Ancillary Service Markets for Power Reserves. Proceedings of IAEE International Conference, Rio de Janeiro. URL: http://www.sintef .no/globalassets/ project / balance - management / paper / timing - of - as - and - short - term-markets _ abassy_2010.pdf.

Amprion (2013). Netzkennzahlen. U R L: http://www.amprion.net/netzkennzahlen (visited on March 12, 2015).

Barrows, C., M. Hummon, W. Jones, and E. Hale (2014). Time Domain Partitioning of Electricity Production Cost Simulations. Technical report NREL/TP-6A20-60969. Golden, CO. U RL: http://www.nrel.gov/docs/fy14osti/60969.pdf (visited on January 2, 2017).

van den Bergh, K., R. Hytowitz, K. Bruninx, E. Delarue, W. D'haeseleer, and B. Hobbs (2016). Benefits of Coordinating Sizing, Allocation and Activation of Reserves Among Market Zones. TME Working Paper - Energy and Environment WP EN2015-14. Leuven. URL: https: //www . mech. kuleuven. be/en/tme/research/energy_environment/Pdf/wpen2015-14v2b.pdf.

BNetzA (2014a). Genehmigung des Szenariorahmens 2025 für die Netzentwicklungsplanung und Offshore-Netzentwicklungsplanung. Bonn, Germany. U RL: http://www.netzausbau.de/Sh aredDocs/Downloads/DE/Delta/Szenariorahmen/Szenariorahmen_2025_Genehmigung . pdf?_-_blob=publicationFile (visited on July 21, 2015).

BNetzA (2014b). Kraftwerksliste der Bundesnetzagentur, Stand 02.04.2014. URL: http: / / www . bundesnetzagentur . de / DE / Sachgebiete / ElektrizitaetundGas / Unternehmen _ 
Institutionen/Versorgungssicherheit/Erzeugungskapazitaeten/Kraftwerksliste/ kraftwerksliste-node.html.

BNetzA (2015). Monitoringbericht 2015. Bonn, Germany. URL: http://www. bundesnetzagen tur.de/SharedDocs/Downloads/DE/Allgemeines/Bundesnetzagentur/Publikationen/ Berichte/2015/Monitoringbericht_2015_BA . pdf ; jsessionid=C0584D0465263328397F 085BFF6884E0?__blob=publicationFile\&v=3 (visited on March 3, 2016).

Böttger, D. and T. Bruckner (2015). Market design improvements in the German balancing power market - A fundamental model analysis. Proceedings of the 10th ENERDAY Conference on Energy Economics and Technology. Dresden.

Böttger, D., M. Götz, M. Theofilidi, and T. Bruckner (2015). Control power provision with powerto-heat plants in systems with high shares of renewable energy sources - An illustrative analysis for Germany based on the use of electric boilers in district heating grids. Energy 82, $157-167$.

Brandstätt, C. (2014). Economics for flexible consumers in balancing markets. Presentation at the 14th IAEE European Conference on Sustainable Energy Policy and Strategies for Europe. URL: http : / / www . iaee . org/en/publications/proceedingsabstractpdf . aspx? id= 12274 (visited on August 27, 2015).

Breuer, C., C. Engelhardt, and A. Moser (2013). Expectation-based reserve capacity dimensioning in power systems with an increasing intermittent feed-in. 10th International Conference on the European Energy Market (EEM 2013). Stockholm, Sweden: IEEE.

Brouwer, A. S., M. van den Broek, A. Seebregts, and A. Faaij (2014). Impacts of large-scale Intermittent Renewable Energy Sources on electricity systems, and how these can be modeled. Renewable and Sustainable Energy Reviews 33, 443-466.

Bucksteeg, M., L. Niesen, P. Himmes, D. Schober, C. Weber, B. Baumgart, T. Plöger, D. Willemsen, D. Nailis, L. Schuffelen, and M. Bittner (2014). Marktdesign für zukunftsfähige Elektrizitätsmärkte unter besonderer Berücksichtigung der vermehrten Einspeisung von erneuerbaren Energien (DESIRE). Endbericht. URL: http://www.bet-aachen.de/fileadmin/ redaktion/PDF/Studien_und_Gutachten/DESIRE_Endbericht__141024_FINAL_Lang . pdf (visited on August 27, 2015).

Bucksteeg, M., L. Niesen, and C. Weber (2016). Impacts of Dynamic Probabilistic Reserve Sizing Techniques on Reserve Requirements and System Costs. IEEE Transactions on Sustainable Energy 7(4), 1408-1420.

Chao, H.-P. and R. Wilson (2002). Multi-dimensional procurement auctions for power reserves: Robust incentive-compatible scoring and settlement rules. Journal of Regulatory Economics $22(2), 161-183$.

dena (2010). dena-Netzstudie II - Integration erneuerbarer Energien in die deutsche Stromversorgung im Zeitraum 2015-2020 mit Ausblick auf 2025. Endbericht. Berlin, Germany. URL: 
http://www.dena.de/fileadmin/user_upload/Publikationen/Erneuerbare/Dokument e/Endbericht_dena-Netzstudie_II.PDF (visited on September 14, 2016).

dena (2014). dena-Studie Systemdienstleistungen 2030 - Sicherheit und Zuverlässigkeit einer Stromversorgung mit hohem Anteil erneuerbarer Energien. Endbericht. Berlin, Germany. UR L: http://www.dena.de/fileadmin/user_upload/Projekte/Energiesysteme/Dokumente/ dena-Studie_Systemdienstleistungen_2030.pdf (visited on September 14, 2016).

DLR (2012). Langfristszenarien und Strategien für den Ausbau der erneuerbaren Energien in Deutschland bei Berücksichtigung der Entwicklung in Europa und global. Schlussbericht BMU - FKZ 03MAP146. 345 pp. URL: http://www.dlr.de/dlr/Portaldata/1/Resources / bilder/portal/portal_2012_1/leitstudie2011_bf .pdf (visited on October 24, 2016).

EC (2017). Commission regulation (EU) establishing a guideline on electricity balancing. Final Draft. Brussels, Belgium. URL: https : / / ec . europa . eu/energy/sites/ener/files / documents/informal_service_level_ebgl_24-01-2017.pdf (visited on January 30, 2017).

Egerer, J., C. Gerbaulet, R. Ihlenburg, F. Kunz, B. Reinhard, C. von Hirschhausen, A. Weber, and J. Weibezahn (2014). Electricity Sector Data for Policy-Relevant Modeling: Data Documentation and Applications to the German and European Electricity Markets. DIW Berlin Data Documentation 72. Berlin, Germany. URL: https://www.diw.de/documents/ publikationen/73/diw_01.c.440963.de/diw_datadoc_2014-072.pdf (visited on September 14, 2016).

ENTSO-E (2013). Network Code on Electricity Balancing. Brussels, Belgium. U R L: https : //www.entsoe.eu/fileadmin/user_upload/_library/resources/BAL/131223_NC_EB_ FINAL.PDF (visited on January 7, 2014).

ENTSO-E (2014). Scenario Outlook 8 Adequacy Forecast 2014-2030. Brussels, Belgium. URL: https : / / www . entsoe . eu / Documents / SDC\%20documents / SOAF / 141031_SOAF\%2020142030_.pdf (visited on September 15, 2016).

ENTSO-E (2013-2016). Consumption Data. URL: https : / / www . entsoe . eu / data / dataportal/consumption/ (visited on October 24, 2016).

EWEA (2014). Economic grid support services by wind and solar PV - a review of system needs, technology options, economic benefits and suitable market mechanisms. Brussels, Belgium. URL: https : / / windeurope . org/fileadmin/files/library/publications/reports / REserviceS.pdf (visited on February 12, 2017).

Farahmand, H. and G. Doorman (2012). Balancing market integration in the Northern European continent. Applied Energy 96. Special Issue "Smart Grids", 316-326.

Farahmand, H., T. Aigner, G. L. Doorman, M. Korpas, and D. Huertas-Hernando (2012). Balancing Market Integration in the Northern European Continent: A 2030 Case Study. IEEE Transactions on Sustainable Energy 3(4), 918-930. 
Fraunhofer IWES (2014). Regelenergie durch Windkraftanlagen. Projekt im Auftrag des Bundesministeriums für Umwelt, Naturschutz, Bau und Reaktorsicherheit. Kassel. U R L: http:// www . energiesystemtechnik. iwes . fraunhofer. de/content/dam/iwes-neu/energiesy stemtechnik/de/Dokumente/Studien-Reports/20140822_Abschlussbericht_rev1.pdf (visited on October 17, 2016).

Gebrekiros, Y., G. Doorman, H. Farahmand, and S. Jaehnert (2013). Benefits of cross-border reserve procurement based on pre-allocation of transmission capacity. PowerTech. Grenoble, France: IEEE.

Gebrekiros, Y., G. Doorman, S. Jaehnert, and H. Farahmand (2015a). Balancing energy market integration considering grid constraints. PowerTech. IEEE, 1-6.

Gebrekiros, Y., G. Doorman, S. Jaehnert, and H. Farahmand (2015b). Reserve procurement and transmission capacity reservation in the Northern European power market. International Journal of Electrical Power 83 Energy Systems 67, 546-559.

Gerbaulet, C., F. Kunz, C. Lorenz, C. von Hirschhausen, and B. Reinhard (2014). Cost-minimal investments into conventional generation capacities under a Europe-wide renewables policy. 11th International Conference on the European Energy Market (EEM), 2014. IEEE.

Gerbaulet, C. and C. Lorenz (2017). dynELMOD: A Dynamic Investment and Dispatch Model for the Future European Electricity Market. DIW Berlin, Data Documentation 88. Berlin, Germany.

Gesino, A. J. (2010). Power reserve provision with wind farms: Grid integrations of wind power. PhD thesis. Kassel, Germany: University of Kassel.

Götz, A. and B. Baumgart (2014). Windenergie am Regelleistungsmarkt. Energiewirtschaftliche Tagesfragen 64(4), 13-17.

Growitsch, C., F. Höffler, and M. Wissner (2010). Marktkonzentration und Marktmachtanalyse für den deutschen Regelenergiemarkt. Zeitschrift für Energiewirtschaft 34(3), 209-222.

Haucap, J., U. Heimeshoff, and D. Jovanovic (2014). Competition in Germany's Minute Reserve Power Market: An Econometric Analysis. The Energy Journal Volume 35(2).

Heim, S. and G. Goetz (2013). Do pay-as-bid auctions favor collusion? - Evidence from Germany's market for reserve power. ZEW Discussion Paper 13-035. UR L: http://ub-madoc.bib.unimannheim.de/33813/1/dp13035.pdf.

Hirth, L. and I. Ziegenhagen (2015). Balancing power and variable renewables: Three links. Renewable and Sustainable Energy Reviews 50, 1035-1051.

Holttinen, H., P. Meibom, A. Orths, B. Lange, M. O’Malley, J. O. Tande, A. Estanqueiro, E. Gomez, L. Söder, G. Strbac, J. C. Smith, and F. van Hulle (2011). Impacts of large amounts of wind power on design and operation of power systems, results of IEA collaboration. Wind Energy 14(2), 179-192. 
Jaehnert, S. and G. Doorman (2010). Modelling an integrated northern European regulating power market based on a common day-ahead market. Proceedings of IAAE's Rio 2010 International Conference. Rio de Janeiro, Brazil.

Just, S. and C. Weber (2008). Pricing of reserves: Valuing system reserve capacity against spot prices in electricity markets. Energy Economics 30(6), 3198-3221.

Just, S. (2011). Appropriate contract durations in the German markets for on-line reserve capacity. Journal of regulatory economics 39(2), 194-220.

Kahn, A. E., P. C. Cramton, R. H. Porter, and R. D. Tabors (2001). Uniform pricing or pay-as-bid pricing: a dilemma for California and beyond. The Electricity Journal 14(6), 70-79.

Knaut, A., F. Obermüller, and F. Weiser (2017). Tender Frequency and Market Concentration in Balancing Power Markets. EWI Working Paper 2017-4. URL: http://econpapers.repec. org/paper/risewikln/2017_5f004.htm (visited on March 29, 2017).

Koliou, E., C. Eid, J. P. Chaves-Ávila, and R. A. Hakvoort (2014). Demand response in liberalized electricity markets: Analysis of aggregated load participation in the German balancing mechanism. Energy 71, 245-254.

Lew, D., G. Brinkman, E. Ibanez, B. M. Hodge, and J. King (2013). The western wind and solar integration study phase 2. Technical Report NREL/TP-5500-55588. Golden, CO, USA. UR L: http://www.nrel.gov/docs/fy13osti/55588.pdf (visited on October 24, 2016).

Lindsjørn, M. V. (2012). A Method for bidding in sequential Capacity Reserve Markets using mixed-integer programming. PhD thesis. Trondheim, Norway: Norwegian University of Science and Technology.

Lorenz, C. and C. Gerbaulet (2014). New Cross-Border Electricity Balancing Arrangements in Europe. DIW Berlin, Discussion Paper 1400. Berlin, Germany. URL: https : / / www . diw.de/documents/publikationen/73/diw_01.c.470807.de/dp1400.pdf (visited on September 15, 2016).

Lorenz, C., I. Schlecht, B. Reinhard, R. Weinhold, and R. Mieth (2014). Assessing inefficiencies on the German balancing market. 11th International Conference on the European Energy Market (EEM14). IEEE.

Mauritzen, J. (2015). Now or Later? Trading Wind Power Closer to Real Time And How Poorly Designed Subsidies Lead to Higher Balancing Costs. The Energy Journal 36(4), 149-164.

Morbee, J., J. Driesen, K. De Vos, and R. Belmans (2013). Impact of wind power on sizing and allocation of reserve requirements. IET Renewable Power Generation 7(1), 1-9.

Müsgens, F., A. Ockenfels, and M. Peek (2011). Economics and design of balancing power markets in Germany. University of Technology Cottbus Working Paper 2011/01. URL: http://www.r2b-energy . at/uploads/pdf/publikationen/WP_2011_01.pdf (visited on November 13, 2013). 
Müsgens, F., A. Ockenfels, and M. Peek (2012). Balancing power markets in Germany: timing matters. Zeitschrift für Energiewirtschaft 36(1).

Müsgens, F., A. Ockenfels, and M. Peek (2014). Economics and design of balancing power markets in Germany. International Journal of Electrical Power \& Energy Systems 55, 392-401.

Niesen, L. and K. Weber (2014). Equilibrium Pricing of reserve power. IAEE European Energy Conference, Sustainable Energy Policy and Strategies for Europe.

Oei, P.-Y., C. Gerbaulet, C. Kemfert, F. Kunz, F. Reitz, and C. von Hirschhausen (2015). Effektive $\mathrm{CO}_{2}$-Minderung im Stromsektor: Klima-, Preis- und Beschäftigungseffekte des Klimabeitrags und alternativer Instrumente. DIW Berlin, Politikberatung kompakt 98. Berlin, Germany. URL: https : / / www . diw . de / documents / publikationen/73/diw_01 . c . 509387 . de / diwkompakt_2015-098.pdf (visited on September 15, 2016).

Ortega-Vazquez, M. A. and D. S. Kirschen (2009). Estimating the spinning reserve requirements in systems with significant wind power generation penetration. IEEE.

Ortner, A. and C. Graf (2013). Multi-market unit-commitment and capacity reserve prices in systems with a large share of hydro power: A case study. 2013 10th International Conference on the European Energy Market (EEM).

Regelleistung.net (2013). Data for control reserve. URL: https://www.regelleistung.net/ip/ action/abrufwert (visited on March 1, 2014).

Schröder, A., F. Kunz, J. Meiß, R. Mendelevitch, and C. von Hirschhausen (2013). Current and Prospective Costs of Electricity Generation until 2050. DIW Berlin, Data Documentation 68. Berlin, Germany. UR L: http://www.diw.de/documents/publikationen/73/diw_01 . c.424566.de/diw_datadoc_2013-068.pdf (visited on July 17, 2013).

Sorknæs, P., A. N. Andersen, J. Tang, and S. Strøm (2013). Market integration of wind power in electricity system balancing. Energy Strategy Reviews 1(3), 174-180.

Spieker, S., J. Kopiske, and G. Tsatsaronis (2016). Flexibilität aus Wind-und Photovoltaikanlagen im Regelenergiemarkt 2035. 14. Symposium Energieinnovation. Graz, Austria.

Swider, D. J. (2007). Simultaneous bidding in day-ahead auctions for spot energy and power systems reserve. International Journal of Electrical Power $\mathcal{B}$ Energy Systems 29(6), 470-479.

TenneT (2013). Netzkennzahlen. URL: https : / / www . tennettso . de/site/Transparenz / veroeffentlichungen/netzkennzahlen (visited on March 12, 2015).

TransnetBW (2013). Kennzahlen. UR L: https://www.transnetbw.de/de/kennzahlen (visited on March 12, 2015).

Umweltbundesamt (2015). Datenbank "Kraftwerke in Deutschland". UR L: http://www . umwe ltbundesamt.de/dokument/datenbank-kraftwerke-in-deutschland (visited on July 2, 2015). 
de Vos, K. and J. Driesen (2015). Active participation of wind power in operating reserves. IET Renewable Power Generation 9(6), 566-575.

Zerrahn, A. and W.-P. Schill (2015). A Greenfield model to evaluate long-run power storage requirements for high shares of renewables. DIW Berlin, Discussion Paper 1457. Berlin, Germany. URL: https://www.diw.de/documents/publikationen/73/diw_01.c. 498475. de/dp1457.pdf (visited on April 19, 2016).

Ziegenhagen, I. (2013). Impact of Increasing Wind and PV Penetration Rates on Control Power Capacity Requirements in Germany. MA thesis. Institut für Infrastruktur und Ressourcenmanagement, Universität Leipzig. 